\title{
Boosting the Rate and Cycling Performance of $\beta$-LixV2O5 Nanorods for Li lon Battery by Electrode Surface Decoration
}

Panpan Wang, Yue Du, Baoyou Zhang, Yanxin Yao, Yuchen Xiao, Lijie Ci, Chengyan Xu, Liang Zhen Submitted date: 10/09/2019 Posted date: 11/09/2019

Licence: CC BY-NC-ND 4.0

Citation information: Wang, Panpan; Du, Yue; Zhang, Baoyou; Yao, Yanxin; Xiao, Yuchen; Ci, Lijie; et al. (2019): Boosting the Rate and Cycling Performance of $\beta$-LixV2O5 Nanorods for Li lon Battery by Electrode Surface Decoration. ChemRxiv. Preprint.

The $\beta$-phase lithium vanadium oxide bronze $\left(\beta-\mathrm{Li}_{\mathrm{x}} \mathrm{V}_{2} \mathrm{O}_{5}\right)$ with high theoretic specific capacity up to $440 \mathrm{mAh}$ $\mathrm{g}^{-1}$ is considered as promising cathode materials, however, their practical application is hindered by its poor ionic and electronic conductivity, resulting in unsatisfied cyclic stability and rate capability. Herein, we report the surface decoration of $\beta-\mathrm{Li}_{\mathrm{X}} \mathrm{V}_{2} \mathrm{O}_{5}$ cathode using both reduced oxide graphene and ionic conductor $\mathrm{LaPO}_{4}$, which significantly promotes the electronic transfer and $\mathrm{Li}^{+}$diffusion rate, respectively. As a result, the $\mathrm{rGO} / \mathrm{LaPO}_{4} / \mathrm{Li}_{\mathrm{x}} \mathrm{V}_{2} \mathrm{O}_{5}$ composite exhibits excellent electrochemical performance in terms of high reversible specific capacity of $275.7 \mathrm{mAh} \mathrm{g}^{-1}$ with high capacity retention of $84.1 \%$ after 100 cycles at a current density of $60 \mathrm{~mA} \mathrm{~g}^{-1}$, and acceptable specific capacity of $170.3 \mathrm{mAh} \mathrm{g}^{-1}$ at high current density of $400 \mathrm{~mA} \mathrm{~g}^{-1}$. The cycled electrode is also analyzed by electrochemical impedance spectroscopy, ex-situ X-ray diffraction and scanning electron microscope, providing further insights into the improvement of electrochemical performance. Our results provide an effective approach to boost the electrochemical properties of lithium vanadates for practical application in lithium ion batteries.

File list (3)

Manuscript.doc (2.58 MiB)

view on ChemRxiv - download file

Manuscript (1).pdf (1.45 MiB) view on ChemRxiv • download file 


\section{Boosting the rate and cycling performance of $\beta-\mathrm{Li}_{x} \mathrm{~V}_{2} \mathrm{O}_{5}$}

\section{nanorods for Li ion battery by electrode surface decoration}

Pan-Pan Wang ${ }^{\mathrm{a}, \mathrm{b}, \mathrm{c}}$, Yue Du ${ }^{\mathrm{a}, \mathrm{c}}$, Bao-You Zhang ${ }^{\mathrm{b}}$, Yan-Xin Yao ${ }^{\mathrm{b}}$, Yu-Chen Xiao ${ }^{\mathrm{b}}$, Li-Jie

$\mathrm{Ci}^{\mathrm{a}}$, Cheng-Yan $\mathrm{Xu}^{\mathrm{a}, \mathrm{b}, \mathrm{c}, *}$, Liang Zhen ${ }^{\mathrm{a}, \mathrm{b}, \mathrm{c}, *}$

${ }^{a}$ School of Materials Science and Engineering, Harbin Institute of Technology (Shenzhen), Shenzhen 518055, China

${ }^{b}$ School of Materials Science and Engineering, Harbin Institute of Technology, Harbin 150001, China

${ }^{c}$ MOE Key Laboratory of Micro-Systems and Micro-Structures Manufacturing, Harbin Institute of Technology, Harbin 150080, China

E-mail: Izhen@hit.edu.cn (L.Z.); cy_xu@hit.edu.cn (C.Y.X.)

Abstract: The $\beta$-phase lithium vanadium oxide bronze $\left(\beta-\mathrm{Li}_{x} \mathrm{~V}_{2} \mathrm{O}_{5}\right)$ with high theoretic specific capacity up to $440 \mathrm{mAh} \mathrm{g}^{-1}$ is considered as promising cathode materials, however, their practical application is hindered by its poor ionic and electronic conductivity, resulting in unsatisfied cyclic stability and rate capability. Herein, we report the surface decoration of $\beta-\mathrm{Li}_{x} \mathrm{~V}_{2} \mathrm{O}_{5}$ cathode using both reduced oxide graphene and ionic conductor $\mathrm{LaPO}_{4}$, which significantly promotes the electronic transfer and $\mathrm{Li}^{+}$diffusion rate, respectively. As a result, the $\mathrm{rGO} / \mathrm{LaPO}_{4} / \mathrm{Li}_{x} \mathrm{~V}_{2} \mathrm{O}_{5}$ composite exhibits excellent electrochemical performance in terms of high reversible specific capacity of $275.7 \mathrm{mAh} \mathrm{g}^{-1}$ with high capacity retention of $84.1 \%$ after 100 cycles at a current density of $60 \mathrm{~mA} \mathrm{~g}^{-1}$, and acceptable specific capacity of $170.3 \mathrm{mAh} \mathrm{g}^{-1}$ at high current density of $400 \mathrm{~mA} \mathrm{~g}^{-1}$. The cycled 
electrode is also analyzed by electrochemical impedance spectroscopy, ex-situ X-ray diffraction and scanning electron microscope, providing further insights into the improvement of electrochemical performance. Our results provide an effective approach to boost the electrochemical properties of lithium vanadates for practical application in lithium ion batteries.

Keywords: $\beta$ - $\mathrm{Li}_{x} \mathrm{~V}_{2} \mathrm{O}_{5}$, cyclic stability, reduced oxide graphene, ionic conductor, surface decoration

\section{Introduction}

Due to the attractive merits of high energy density, long cyclic life and environmental friendliness, rechargeable lithium ion batteries (LIBs) have been widely used as power source for portable electronic devices.[1-3] Despite that, the energy and power density of current commercial LIBs was still far from satisfying the urgent requirements for further applications in electric vehicles and smart grids. The limited capacity of commonly used cathodes, including $\mathrm{LiCoO}_{2}, \mathrm{LiFePO}_{4}, \mathrm{LiMn}_{2} \mathrm{O}_{4}$ and Li-excess layered oxide compounds, is the main limiting factor for the realization of high energy-density LIBs, which delivered lower reversible capacities $\left(<280 \mathrm{mAh} \mathrm{g}^{-1}\right)$ than the counterpart graphite anode. To this end, cathode material with higher specific capacity are urgently needed to meet the ever-increasing goals for high energy-density LIBs. $[4,5]$

Recently, vanadium oxides and their derivatives have received tremendous attention due to their rich chemistry and high specific capacity as LIBs cathode. [6-8] As for $\mathrm{V}_{2} \mathrm{O}_{5}$, its theoretical capacity reaches up to $440 \mathrm{mAh} \mathrm{g}^{-1}$ because 
more than 3 lithium ions per formula can be inserted into $\mathrm{V}_{2} \mathrm{O}_{5}$ layer, whereas the capacity of $\mathrm{V}_{2} \mathrm{O}_{5}$ cathode decays seriously after initial cycling due to the irreversible phase transformation and local structure collapse when the lithium uptakes more than 2 moles per formula unit.[9, 10] Different from layered $\mathrm{V}_{2} \mathrm{O}_{5}, \beta$-phase vanadium oxide bronzes $\left(\beta-\mathrm{M}_{x} \mathrm{~V}_{2} \mathrm{O}_{5}, \mathrm{M}=\right.$ alkali, alkaline earth, and transition metals) adopts more stable and rigid crystal structures with the $\left[\mathrm{VO}_{6}\right]$ octahedrons layers pillared by $\left[\mathrm{VO}_{5}\right]$ square pyramids.[11] The unique 3D framework contained several feasible interstitial sites in the tunnel structure, endowing the vanadium oxide bronzes rather good structural reversibility upon large amount of lithium accommodation, while maintaining high capacity features. [12-15] Despite these advantages, one major drawback of pure $\beta$ phase vanadate cathode is its inferior rate capability and cycling stability,[16, 17] which was believed to be related with its intrinsic poor electronic conductivity and relatively slow $\mathrm{Li}^{+}$diffusion kinetic, especially upon deep lithiation. Meanwhile, the fragile interfacial property of pristine vanadate electrode with the risk of erosion from the electrolytes and vanadium dissolution is considered to be another reason for capacity fading.[18] Thus, modification strategies are imperative to overcome these limitations, thereby boosting the electrochemical properties of lithium vanadate cathode.[19]

Surface modification with conducting materials (e.g., graphene,[20, 21] polymer,[22, 23]) or ionic conductors (phosphates,[24] metal oxides,[25, 26] etc.) is proved to be efficient to enhance the electrochemical properties of 
vanadate oxide cathode. Recently, two-dimensional graphene-based materials were emerging as an eye-catching coating candidate with superior electrical conductivity, which was usually hybrid with active materials through hydrothermal route or calcination treatment in reductive atmosphere. Whereas the coexisted $\mathrm{V}^{4+}$ and $\mathrm{V}^{5+}$ in $\beta-\mathrm{Li}_{x} \mathrm{~V}_{2} \mathrm{O}_{5}$ are susceptible to the reductive graphene during the hybridization process especially under high calcination temperature, resulting in undesired impurity phase or even inducing irreversible phase transition and thus capacity loss of the cathode. To achieve a uniform graphene coating layer on $\beta-\mathrm{Li}_{x} \mathrm{~V}_{2} \mathrm{O}_{5}$ with complex valence states while maintain the $\beta$ $\mathrm{Li}_{x} \mathrm{~V}_{2} \mathrm{O}_{5}$ phase is still a big challenge. Herein, a gentle freeze drying strategy with ionic conductor decoration was applied successfully to tackle these issues.

In this work, the conductive reduced oxide graphene (rGO) and ionic conductor $\mathrm{LaPO}_{4}$ were employed to engineer the interfacial chemistry of $\beta$ $\mathrm{Li}_{x} \mathrm{~V}_{2} \mathrm{O}_{5}$ cathode via chemical precipitation route followed by frozen dryness. The obtained $\mathrm{rGO} / \mathrm{LaPO}_{4} / \mathrm{LVO}$ electrode demonstrated remarkable cycling stability and superior rate capability with specific $\mathrm{Li}^{+}$multiple-insertion mechanism, which was attributed to the assistance of conductive rGO and ionic conductor $\mathrm{LaPO}_{4}$ layer, with the ability to promote electronic transfer and $\mathrm{Li}^{+}$ diffusion coefficient between active nanorods efficiently.

\section{Experimental section}

\subsection{Synthesis of $\beta-L i_{x} V_{2} O_{5}$ nanorods}

The $\beta-\mathrm{Li}_{x} \mathrm{~V}_{2} \mathrm{O}_{5}$ nanorods were obtained by a facile hydrothermal route followed by 
calcination treatment.[15] Briefly, $0.1 \mathrm{~g} \mathrm{~V}_{2} \mathrm{O}_{5}$ and $3.0 \mathrm{~g} \mathrm{LiNO}_{3}$ were added into $30 \mathrm{~mL}$ de-ionized water with vigorously stirring. Then, the orange-yellow suspension was transferred into $50 \mathrm{~mL}$ Teflon-lined stainless autoclave and heated at $220{ }^{\circ} \mathrm{C}$ for $24 \mathrm{~h}$. The precursor was collected by centrifugation and washed with absolute ethanol for several times, which was calcinated at $600{ }^{\circ} \mathrm{C}$ for $3 \mathrm{~h}$ under $\mathrm{Ar}$ atmosphere. The final product was denoted as LVO.

\section{2 $\mathrm{LaPO}_{4}$ coating and rGO wrapping}

The surface modification of $\beta-\mathrm{Li}_{x} \mathrm{~V}_{2} \mathrm{O}_{5}$ nanorods was implemented by a two-step process involving chemical precipitation and frozen dryness. Firstly, $90 \mathrm{mg}$ LVO powder was dispersed into $0.1 \mathrm{M} \mathrm{La}\left(\mathrm{NO}_{3}\right)_{3} \cdot 6 \mathrm{H}_{2} \mathrm{O}$ (Aldrich, 99.99\%) and $\mathrm{NH}_{4} \mathrm{H}_{2} \mathrm{PO}_{4}$ solution with continuous stirring for $24 \mathrm{~h}$, which was evaporated at room temperature and calcinated at $400{ }^{\circ} \mathrm{C}$ for $3 \mathrm{~h}$ under $\mathrm{Ar}$ atmosphere. The corresponding products were denoted as $\mathrm{LaPO}_{4} / \mathrm{LVO}$. Subsequently, the obtained $\mathrm{LaPO}_{4} / \mathrm{LVO}$ powder was dispersed into $20 \mathrm{~mL} 0.5 \mathrm{M}$ rGO solution by vigorous stirring, which was frozen quickly by liquid nitrogen and frozen dried overnight. The final product was obtained with heat treatment at $180{ }^{\circ} \mathrm{C}$ for $2 \mathrm{~h}$ under $\mathrm{Ar}$ atmosphere and labeled as $\mathrm{rGO} / \mathrm{LaPO}_{4} / \mathrm{LVO}$. Herein, the rGO nanosheets were prepared from natural graphite powders by Hummer’s method.[27, 28]

\subsection{Characterization of morphology and structure}

The crystal structure of the obtained products was performed by X-ray diffraction (XRD, Rigaku D/Max2500 with $\mathrm{Cu} \mathrm{K}_{\alpha}$ radiation) and Raman spectra (Jobin Yvon Horiba with He-Ne laser, $632.9 \mathrm{~nm}$ ). The morphology characterization was collected 
by field-emission scanning electron microscope (FE-SEM, FEI Quanta 200F), and transmission electron microscope (TEM, JEM 2100, $200 \mathrm{kV}$ ), respectively. The chemical valence was analyzed by X-ray photoelectron spectroscopy (XPS, ThermoFisher). The binding energy of XPS was corrected by adjusting the C 1s photoelectron peak at $284.8 \mathrm{eV}$ for the reference.

\subsection{Electrochemical measurements}

The electrochemical performance of $\beta-\mathrm{Li}_{x} \mathrm{~V}_{2} \mathrm{O}_{5}$ electrode before and after surface modification was evaluated using CR2025-type coin cells, which were assembled in an Ar-filled glovebox (Germany, MBraun) with the contents of $\mathrm{H}_{2} \mathrm{O}$ and $\mathrm{O}_{2}$ less than 5 ppm. The cathode was fabricated by mixing the active material, conductive agent and PVDF binder in the weight ratios of $8: 1: 1$ and pasted onto Al foils, which was punched into round disk with diameter of $14 \mathrm{~mm}$ after vacuum dryness. $1 \mathrm{M} \mathrm{LiPF}_{6}$ dissolved in ethylene carbonate/ethyl methyl carbonate/dimethylcarbonate (EC/EMC/DMC $1: 1: 1$ in volume ratio) solvent was adopted as the electrolyte. The lithium metal was employed as the counter/reference electrode and the porous polypropylene films were served as separator, respectively.

The charge/discharge tests were carried out on LAND multi-channel battery testing system (CT2001A, Jinnuo Wuhan Corp., China) in the potential range of 1.84.0 V (vs. $\mathrm{Li} / \mathrm{Li}^{+}$). Both cyclic voltammetry (CV) and electrochemical impedance spectroscopy (EIS) tests were operated on electrochemical workstation (CHI660E). The scan rate of $\mathrm{CV}$ was set as $0.05 \mathrm{mV} \mathrm{s}^{-1}$ and the frequency of EIS ranged from 100 $\mathrm{kHz}$ to $0.01 \mathrm{~Hz}$, respectively. For the SEM and XRD test of the cycled electrode, the 
coin cells were disassembled in Ar-filled glove box and rinsed in DMC solvent repeatedly.

\section{Results and discussion}

\subsection{Characterization of $\mathrm{rGO} / \mathrm{LaPO}_{4} / \mathrm{LVO}$ nanorods}

In the crystal structure of $\beta-\mathrm{Li}_{x} \mathrm{~V}_{2} \mathrm{O}_{5}$ (Figure 1a), there are three different vanadium sites marked with different colours, namely, $V(1), V(2)$, and $V(3)$. The edge-sharing $\mathrm{V}(1) \mathrm{O}_{6}$ octahedra and corner-sharing $\mathrm{V}(2) \mathrm{O}_{6}$ octahedra constitute $\left[\mathrm{V}_{4} \mathrm{O}_{11}\right]_{n}$ layers along the $b$ axis in form of zigzag chains and double chains (projection along the $a$-axis in Figure 1b), respectively, and the five-fold $\mathrm{V}(3) \mathrm{O}_{5}$ pyramids chains were acted as pillars to connect the layers by cornershared oxygen. The formed tunnel-like $\beta$ phase vanadium oxide bronzes can facilely accommodate a large amount of $\mathrm{Li}^{+}$by the successive filling of different crystallographic sites in the tunneled host structure. Whereas the complicated crystal structure is ease to be transformed by the partial reduction or oxidation of the framework vanadium atoms, giving rise to undesired impurity phase. The XRD pattern of the rGO/LVO sample prepared by ovendrying was provided in Figure S1. Obviously, strong diffraction of $\mathrm{LiV}_{3} \mathrm{O}_{8}$ phase was detected in the $\mathrm{rGO} / \beta-\mathrm{Li}_{x} \mathrm{~V}_{2} \mathrm{O}_{5}$ sample, suggesting the unstable phase structure when dried in heating environment with reduced graphene oxide nanosheets. By comparison, the XRD patterns of the $\mathrm{rGO} / \mathrm{LaPO}_{4} / \mathrm{LVO}$ sample obtained by gentle frozen dryness were displayed in Figure 1c. The hydrothermal synthesized product labeled as LVO were assigned to the 
monoclinic $\beta-\mathrm{Li}_{x} \mathrm{~V}_{2} \mathrm{O}_{5}$ phase (JCPDS no. 73-1670). Noticeably, the modification samples of $\mathrm{LaPO}_{4} / \mathrm{LVO}$ and $\mathrm{rGO} / \mathrm{LaPO}_{4} / \mathrm{LVO}$ exhibit identical diffraction peaks with that of $\beta-\mathrm{Li}_{x} \mathrm{~V}_{2} \mathrm{O}_{5}$ phase.[29] Herein, the well-preserved $\beta-\mathrm{Li}_{x} \mathrm{~V}_{2} \mathrm{O}_{5}$ phase after modification with electronic conductive rGO and ionic conductive $\mathrm{LaPO}_{4}$ further demonstrate that the frozen dryness strategy was effective to be applied in the surface modification for the vanadate compound with complex valence states. Besides, the diffraction peak of rGO and $\mathrm{LaPO}_{4}$ was absent in the XRD pattern, which was probably because of the relatively low diffraction intensity of rGO and trace amount of $\mathrm{LaPO}_{4}$.

The morphology of $\mathrm{rGO} / \mathrm{LaPO}_{4} / \mathrm{LVO}$ was characterized by SEM and TEM, and the results are shown in Figure 1d-f. It can be clearly seen that the LVO nanorods were about $300-500 \mathrm{~nm}$ in average diameter and $1-1.5 \mu \mathrm{m}$ in average length. LVO nanorods were well wrapped by reduced graphene oxide nanosheets without aggregation, which would bridge the electrical connection between the dispersed LVO nanorods effectively (Figure 1d). Noticeably, tiny nanoparticles were observed on the surface of LVO nanorods with $\mathrm{LaPO}_{4}$ coating even if the rods are wrapped by rGO nanosheets. From TEM image in Figure 1e, it can be seen that the LVO nanorods were covered by a crystalline layer with thickness of about $20 \mathrm{~nm}$. The high-resolution TEM image of LVO rods surface particle shown in Figure 1f presented a clear interplanar spacing lattice of $0.488 \mathrm{~nm}$ that was in agreement with the (110) crystal planes of the monoclinic $\mathrm{LaPO}_{4}$ phase, further proving that $\mathrm{LaPO}_{4}$ layer is successfully 
coated onto the LVO surface. Meanwhile, the energy dispersive X-ray spectroscopy (EDX) mapping of $\mathrm{rGO} / \mathrm{LaPO}_{4} / \mathrm{LVO}$ was displayed in Figure S2. As shown, the elements La and P were detected, which exhibit almost the same distribution with the elements $\mathrm{V}$ and $\mathrm{O}$. As shown, frozen dryness by liquid nitrogen freeze is a facile approach to realize the cooperation of reduced oxide graphene nanosheets with LVO rods.

Raman spectra of $\mathrm{LVO}$ and the $\mathrm{rGO} / \mathrm{LaPO}_{4} / \mathrm{LVO}$ sample were provided in Figure S3. Four prominent Raman bands around 143, 262, 514, 699 and 1005 $\mathrm{cm}^{-1}$ were observed. The frequency mode of 143 and $262 \mathrm{~cm}^{-1}$ in lower wavenumbers range was assigned to the bond bending vibrations and the frequency mode of 514, 699 and $1005 \mathrm{~cm}^{-1}$ in higher wavenumbers range were designated to the stretching vibrations of differing $\mathrm{V}-\mathrm{O}$ bonds, which was in good accordance with the Raman characteristic peaks of $\beta$-phase bronze $\mathrm{Li}_{x} \mathrm{~V}_{2} \mathrm{O}_{5}$ compounds.[15, 30] Besides, two typical D and $\mathrm{G}$ bands of graphene at 1340 and $1600 \mathrm{~cm}^{-1}$ were presented in the $\mathrm{rGO} / \mathrm{LaPO}_{4} / \mathrm{LVO}$ composite, which originated from the defects of disordered $\mathrm{sp}^{2}$ carbon atoms and graphite carbon, respectively.[31] The intensity ratio of $I_{\mathrm{D}} / I_{\mathrm{G}}$ was estimated to be 0.99 , suggesting the high quality of graphene in the $\mathrm{rGO} / \mathrm{LaPO}_{4} / \mathrm{LVO}$ composite.

The elemental valence states information in pristine LVO and modified samples were investigated by X-ray photoelectron spectroscopy. The XPS spectra of pristine $\mathrm{LVO}, \mathrm{LaPO}_{4} / \mathrm{LVO}$ and $\mathrm{rGO} / \mathrm{LaPO}_{4} / \mathrm{LVO}$ samples were provided in Figure 2a. As seen, the characteristic peak of lithium, vanadium and oxygen can be detected for all the prepared samples. Noticeably, the P2p peak centered at $102.1 \mathrm{eV}$ and the La3d peak located around $836 \mathrm{eV}$ can be observed on the XPS spectrum for $\mathrm{LaPO}_{4} / \mathrm{LVO}$ and $\mathrm{rGO} / \mathrm{LaPO}_{4} / \mathrm{LVO}$ sample, 
indicating the existence of $\mathrm{LaPO}_{4}$ component after surface modification. The high-resolution V2p spectra of the products before and after modification are displayed in Figure 2b. As shown, the V2p spectrum was composed of two characteristic peaks of $\mathrm{V} 2^{3 / 2}$ and $\mathrm{V} 2 \mathrm{p}^{1 / 2}$ located at 517.4 and $524.9 \mathrm{eV}$, respectively. Notably, both of the $\mathrm{V} 2 \mathrm{p}^{3 / 2}$ and $\mathrm{V} 2 \mathrm{p}^{1 / 2}$ peak can be deconvoluted into two components with the strong one from the pentavalent state $\left(\mathrm{V}^{5+}\right)$ and the weak one from the tetravalent state $\left(\mathrm{V}^{4+}\right)$.[32] Based on the peak areas, the ratio of $\mathrm{V}^{4+}$ to $\mathrm{V}^{5+}$ in $\mathrm{LVO}$ sample was calculated to be 0.218 , which increase to 0.367 after surface modification with $\mathrm{rGO}$ and $\mathrm{LaPO}_{4}$. The slight increase of $\mathrm{V}^{4+}$ on the surface is reasonable because of the existence of reductive oxide graphene when annealed in the inert atmosphere, which might be beneficial for the electronic transfer with more pathways for electron hopping between $\mathrm{V}^{5+}$ and $\mathrm{V}^{4+}$.[33] Additionally, the characteristic XPS peak of La3d located at 839.0 $\mathrm{eV}$ along with a satellite peak around $835.8 \mathrm{eV}$ was detected in the rGO/LaPO $4 / \mathrm{LVO}$ composites (Figure 2c), further verifying the existence of $\mathrm{LaPO}_{4}$ coating layer.[34]

\subsection{Electrochemical properties of $\mathrm{rGO} / \mathrm{LaPO}_{4} / \mathrm{LVO}$ cathode}

In order to investigate the electrochemical behavior of $\beta-\mathrm{Li}_{x} \mathrm{~V}_{2} \mathrm{O}_{5}$ electrode after surface modification, the $\mathrm{CV}$ curves of $\mathrm{LVO}$ and $\mathrm{rGO} / \mathrm{LaPO}_{4} / \mathrm{LVO}$ electrodes were recorded at a scan rate of $0.05 \mathrm{mV} \mathrm{s}^{-1}$ in voltage range of $1.8-$ 4.0 V (vs. $\mathrm{Li} / \mathrm{Li}^{+}$). As shown in Figure 3a, five distinct reduction peaks located at 3.60, 3.42, 2.87, 2.56, $1.90 \mathrm{~V}$ were observed for LVO electrode, corresponding to the $\mathrm{Li}^{+}$successive occupation processes of the specific lithium sites in tunneled framework.[14] For the pristine LVO electrode, large potential 
gap of around $0.36 \mathrm{~V}$ was observed for the redox peaks located at 2.92/2.56 V. In comparison, smaller potential difference of $0.23 \mathrm{~V}$ was displayed for the $\mathrm{rGO} / \mathrm{LaPO}_{4} / \mathrm{LVO}$ composite, implying that the electrochemical polarization was significantly alleviated and the charge transfer reactivity was improved with the conductive rGO layer. The complicated multistep $\mathrm{Li}^{+}$insertion/extraction processes in vanadate electrode were derived from the energy differences for Li-ion holding in different Li sites.[35] Noticeably, the redox peak pairs centered at 2.87/2.91 V was absent in the CV curves of pristine LVO electrode, indicating the difficult extractions of lithium ions from the $\beta$ vanadium bronze structure, while that was clearly observed for $\mathrm{rGO} / \mathrm{LaPO}_{4} / \mathrm{LVO}$ electrode, further demonstrating that the multi-step intercalation and deintercalation of lithium ion in tunneled structure LVO was highly reversible with the presence of rGO and $\mathrm{LaPO}_{4}$ layer. From the $\mathrm{CV}$ curves of $\mathrm{rGO} / \mathrm{LaPO}_{4} / \mathrm{LVO}$ electrode with sharper redox peak and smaller redox potential difference, we can conclude that the $\mathrm{Li}^{+}$intercalation process was facilitated effectively by the assistance of rGO and $\mathrm{LaPO}_{4}$ layer.

Next, the electrochemical performance of $\mathrm{rGO} / \mathrm{LaPO}_{4} / \mathrm{LVO}$ electrode were evaluated. The charge/discharge profiles of the LVO and $\mathrm{rGO} / \mathrm{LaPO}_{4} / \mathrm{LVO}$ electrodes cycled in the voltage window of $1.8-4.0 \mathrm{~V}$ at $60 \mathrm{~mA} \mathrm{~g}^{-1}$ was plotted in Figure 3b and c. Five distinct discharge voltage plateaus around 3.6 V, 3.4 V, 2.8 V, 2.4 V and $1.9 \mathrm{~V}$ were observed, which was in good accordance with the CV curves, relating to the successive $\mathrm{Li}$ insertion steps into LVO tunneled 
crystal structure. Noticeably, the primary charge/discharge potential gap for $\mathrm{rGO} / \mathrm{LaPO}_{4} / \mathrm{LVO}$ electrode $(0.16 \mathrm{~V})$ was much smaller than the LVO electrode (0.3 V), further implying the alleviated electrochemical reaction polarization by surface modification. Meanwhile, the multiple charge/discharge voltages for $\mathrm{rGO} / \mathrm{LaPO}_{4} / \mathrm{LVO}$ electrode were highly overlapped with clearly visible voltage plateaus during cycling (Figure 3c), which suffered from serious voltage decay for LVO electrode (Figure 3b), implying the gradual lithium trapping in the host lattice due to the sluggish $\mathrm{Li}^{+}$diffusion kinetics. The elevated electrochemical kinetics was exclusively due to highly conductive graphene matrix with large area, which could effectively facilitate the electronic transfer by providing more electric contact area between the active LVO nanorods.[36, 37]

To provide an intuitive observation of the intricate Li ordering steps in $\beta$ $\mathrm{Li}_{x} \mathrm{~V}_{2} \mathrm{O}_{5}$, the crystal structure of $\beta-\mathrm{Li}_{x} \mathrm{~V}_{2} \mathrm{O}_{5}$ with possible $\mathrm{Li}^{+}$tunnel sites was illustrated in Figure 3d. For the $\beta-\mathrm{Li}_{x} \mathrm{~V}_{2} \mathrm{O}_{5}$, the pre-inserted $\mathrm{Li}^{+}$were randomly half-occupied in the tunnel sites that labeled M1 with the stoichiometric composition $x=0.33$ according to Wadsley. [38] Meanwhile, there also existed three alternative interstatial sites for $\mathrm{Li}^{+}$intercalation: eight-coordinated sites M2, tetrahedral sites M3, and octahedral sites M4 as shown in Figure 3d with different colors.[39] During the discharge process, the M2 and M3 sites would be half-occupied preferentially by inserted $\mathrm{Li}^{+}$which was governed by the repulsive coulometric interactions between neighboring sites. When the M1, M2, M3 tunnel sites are fully occupied, the filling of octahedral sites M4 would 
be possible, which corresponds to the last voltage plateau as shown in Figure 3b. Of particular note, the $\mathrm{Li}^{+}$filling step of $\mathrm{M} 4$ sites with the voltage plateau around $2 \mathrm{~V}$ was well-maintained for the $\mathrm{rGO} / \mathrm{LaPO}_{4} / \mathrm{LVO}$ electrode even after 100 cycles, further demonstrating the enhanced electrochemical reaction dynamics in $\beta-\mathrm{Li}_{x} \mathrm{~V}_{2} \mathrm{O}_{5}$ after surface modification.

Further, the cycling performance of $\mathrm{LVO}$ and $\mathrm{rGO} / \mathrm{LaPO}_{4} / \mathrm{LVO}$ electrodes at a current density of $60 \mathrm{~mA} \mathrm{~g}^{-1}$ was evaluated as shown in Figure 3e. The pristine LVO electrode delivered an initial discharge capacity of $282.5 \mathrm{mAh} \mathrm{g}^{-1}$, whereas suffered from serious capacity decay with relatively low capacity retention of 37.3\% after 100 cycles. The severe capacity fades mainly originated from the poor intrinsic conductivity as well as potential vanadium dissolution for pristine LVO particles.[40] It was worth mentioning that the cyclic stability of LVO was enhanced dramatically when the coating of $\mathrm{LaPO}_{4}$ and rGO layer was introduced, which delivered high capacity retention up to $84.1 \%$ at a slight expense of specific capacity (275.7 mAh g${ }^{1}$ ). The cyclic stability of LVO electrode was boosted with the surface modified by protective and conductive layer, which was probably derived from the protective coating layer with the ability to prevent the electrode from electrolyte erosion as well as stabilize the crystal structure.[41]

On the other hand, surface modification with conductive rGO and ionic conductive $\mathrm{LaPO}_{4}$ is expected to facilitate the electrochemical reaction dynamics, so we also explore the rate capability of $\mathrm{LVO}$ and $\mathrm{rGO} / \mathrm{LaPO}_{4} / \mathrm{LVO}$ electrodes at different charge/discharge current densities as shown in Figure 3f. The LVO sample delivers specific discharge capacities of 321.9, 252.4, 193.7, 139.2, 93.4 and $48.2 \mathrm{mAh} \mathrm{g}^{-1}$ at current densities of 15, 30, 60, 100, 200 and $400 \mathrm{~mA} \mathrm{~g}^{-1}$, respectively. Significant capacity decay was exhibited for pristine LVO electrode with the current density 
increasing. For the case of $\mathrm{rGO} / \mathrm{LaPO}_{4} / \mathrm{LVO}$ electrode, the specific discharge capacities were 315.8, 263.2, 226.3, 203.3, 186.6 and $170.3 \mathrm{mAh} \mathrm{g}^{-1}$ at current densities of 15, 30, 60, 100, 200 and $400 \mathrm{~mA} \mathrm{~g}^{-1}$, respectively. When the current density was set back to $15 \mathrm{~mA} \mathrm{~g}^{-1}$, as high as $291.3 \mathrm{mAh} \mathrm{g}^{-1}$ can be recovered for the $\mathrm{rGO} / \mathrm{LaPO}_{4} / \mathrm{LVO}$ electrode. It was worth to mention that the capacity varied slightly under every current density for the modification sample. In order to make an intuitive observation of the improved rate capability for modification electrode, the discharge curves of the $\mathrm{LVO}$ and $\mathrm{rGO} / \mathrm{LaPO}_{4} / \mathrm{LVO}$ electrode at different current densities were displayed in Figure S4a and b. Five discharge plateaus corresponding to the successive Li ordering processes in the $\beta$ tunnel framework were observed evidently on the discharge profiles for LVO electrode at $15 \mathrm{~mA} \mathrm{~g}^{-1}$, which experienced noticeable voltage recession with the growing current density, implying the gradual capacity loss derived from lithium trapping in the host lattice due to the sluggish $\mathrm{Li}^{+}$ diffusion kinetics especially under high current densities.[42] For comparison, the discharge plateau was still distinct for $\mathrm{rGO} / \mathrm{LaPO}_{4} / \mathrm{LVO}$ electrode at current density up to $400 \mathrm{~mA} \mathrm{~g}^{-1}$, which is capable of delivering $\sim 75 \%$ of the reversible capacity discharged at $60 \mathrm{~mA} \mathrm{~g}^{-1}$, further suggesting the dramatically improved rate capability of LVO electrode with surface modification. The high rate capability and stable cyclability makes the $\mathrm{rGO} / \mathrm{LaPO}_{4} / \mathrm{LVO}$ composite competitive candidate for lithium ion batteries applications.

\subsection{Mechanism insight of electrochemical performance improvement}

To further clarify the improved electrochemical performance of $\mathrm{rGO} / \mathrm{LaPO}_{4} / \mathrm{LVO}$ electrode, EIS was carried out to analyze the variation of electrode/electrolyte interface property during cycling. The Nyquist plots of $\mathrm{LVO}$ and $\mathrm{rGO} / \mathrm{LaPO}_{4} / \mathrm{LVO}$ electrode after initial cycling were provided in Figure 4a. Both of the curves were composed of a semicircle in the high frequency followed by a straight line in the low 
frequency region, which are assigned to the charge transfer resistance $\left(R_{\mathrm{ct}}\right)$ on the electrode/electrolyte interface and the $\mathrm{Li}^{+}$diffusion within the bulk electrode materials, respectively.[43, 44] The resistance values of the LVO and $\mathrm{rGO} / \mathrm{LaPO}_{4} / \mathrm{LVO}$ electrodes were fitted by the equivalent circuit inset in Figure 4a. The fitting data were shown in Table 1. Obviously, the $R_{\mathrm{ct}}$ value of $\mathrm{rGO} / \mathrm{LaPO}_{4} / \mathrm{LVO}$ (98.2 $\Omega$ ) is three times lower than that of the LVO electrode (379.8 $\Omega$ ), implying the charge transfer resistance was reduced effectively upon rGO modification. Even after 100 cycles (shown in Figure 4b), the $\mathrm{rGO} / \mathrm{LaPO}_{4} / \mathrm{LVO}$ electrode still exhibits much lower $R_{\mathrm{ct}}$ than that of the LVO electrode, further indicating that the introduction of rGO and $\mathrm{LaPO}_{4}$ layer could stabilize the electrode/electrolyte interface, which contribute to the superior cyclic stability and rate capability during charge/discharge processes. The Li ion diffusion coefficient can be calculated by the following equation:[45]

$$
D_{L i+}=0.5 R^{2} T^{2} / S^{2} n^{4} F^{4} C^{2} \sigma^{2}
$$

where $R$ is the gas constant $\left(8.314 \mathrm{~J} \mathrm{~mol}^{-1} \mathrm{~K}^{-1}\right), T$ is the temperature (298 $\left.\mathrm{K}\right), S$ is the electrode area $\left(1.54 \mathrm{~cm}^{2}\right), n$ is the number of electron transfer, $F$ is the Faraday constant (96500 C mol${ }^{-1}$ ), $C$ is the molar concentration of the $\mathrm{Li}^{+}$in the cathode calculated on the basis of the crystallographic cell parameter of LVO, and $\sigma$ is the Warburg impedance coefficient obtained from the slope of fitting lines as shown in Figure 4c. The $\mathrm{Li}^{+}$diffusion coefficient of $\mathrm{rGO} / \mathrm{LaPO}_{4} / \mathrm{LVO}$ is calculated to be $4.67 \times 10^{-14} \mathrm{~cm}^{2} \mathrm{~s}^{-1}$, which is approximately one order higher than that of pristine LVO $\left(2.08 \times 10^{-15} \mathrm{~cm}^{2} \mathrm{~s}^{-1}\right)$. The evidently increased $\mathrm{Li}^{+}$diffusion coefficient suggests that the surface layer of $\mathrm{LaPO}_{4}$ is favorable to accelerate the diffusion of lithium ions and enhance the reversibility of lithium ion insertion/extraction in tunnel structure.[46]

To highlight the advantages of surface engineering on LVO electrode, the differential capacity $(\mathrm{dQ} / \mathrm{d} V)$ plots of $\mathrm{LVO}$ and $\mathrm{rGO} / \mathrm{LaPO}_{4} / \mathrm{LVO}$ electrodes after 100 
cycles were presented in Figure 4d. Obviously, strong and sharp redox peaks were still observed evidently on the $\mathrm{dQ} / \mathrm{dV}$ curves for the $\mathrm{rGO} / \mathrm{LaPO}_{4} / \mathrm{LVO}$ electrode even after 100 cycles, which almost disappeared for the pristine LVO accompanied by serious capacity decay, further revealing that surface co-modification was effective to improve the reversibility of repeated lithium ion insertion/extraction in LVO cathode.

Furthermore, XRD and SEM characterization was utilized to investigate the change of crystal structure and morphology during cycling. Figure 5a shows the XRD patterns of the $\mathrm{LVO}$ and $\mathrm{rGO} / \mathrm{LaPO}_{4} / \mathrm{LVO}$ electrodes before and after 100 cycles. For the cycled LVO electrode, the main diffraction peak intensity of (002) plane was rather weak, which was still maintained sharp and strong for the modified LVO electrode, suggesting the crystal structure was well-preserved upon cycling, which was primarily benefited by the effective protection of crystal structure from electrolyte corrosion by surface modification layer. Figure 5c and e shows the SEM images of the $\mathrm{LVO}$ and $\mathrm{rGO} / \mathrm{LaPO}_{4} / \mathrm{LVO}$ electrodes after 100 cycles. Inevitably, cracks occurred on the LVO nanorods surface induced by the structural stress during lithiation processes, while intact nanorod surface was preserved for $\mathrm{rGO} / \mathrm{LaPO}_{4} / \mathrm{LVO}$ electrodes even after long-term cycling as shown in Figure 5e, further verifying the improved structural stability and reversibility for the modified LVO electrode.

Based on above discussion, the interfacial schematic illustration of LVO with rGO and $\mathrm{LaPO}_{4}$ surface layer is schematically demonstrated in Figure 6. The LVO nanorods was distributed uniformly on the conductive rGO matrix. During discharge process, the electronic transmission between the active LVO nanorods was promoted efficiently through rGO layer which act as "bridge" to connect the adjacent LVO nanorods together. Meanwhile, the interfacial $\mathrm{Li}^{+}$diffusion between the bulk LVO electrode and electrolyte was also facilitated by the $\mathrm{LaPO}_{4}$ layer, which was favorable for the excellent rate capability. Additionally, the protective layer of $\mathrm{LaPO}_{4}$ and $\mathrm{rGO}$ 
would stabilize the electrode/electrolyte interface and protect the LVO particles from electrolyte corrosion, contributing to the improved structural stability and cyclic stability during repeated Li insertion/extraction processes.

\section{Conclusions}

To summarize, we successfully prepared $\mathrm{rGO} / \mathrm{LaPO}_{4} / \mathrm{Li}_{x} \mathrm{~V}_{2} \mathrm{O}_{5}$ composite electrode via chemical precipitation and frozen dryness. The $\mathrm{rGO} / \mathrm{LaPO}_{4} / \mathrm{LVO}$ composite demonstrated significantly improved cyclic stability and rate capability. At a current density of $60 \mathrm{~mA} \mathrm{~g}^{-1}$, the $\mathrm{rGO} / \mathrm{LaPO}_{4} / \mathrm{LVO}$ electrode delivered high reversible capacity of $275.7 \mathrm{mAh} \mathrm{g}^{-1}$ with high capacity retention of $84.1 \%$ after 100 cycles. The enhanced electrochemical performance of the LVO electrode is ascribed to the promoted electronic transfer and $\mathrm{Li}^{+}$diffusion coefficient between active nanorods with the functionality of conductive rGO and $\mathrm{LaPO}_{4}$ layer. The excellent electrochemical properties of $\mathrm{rGO} / \mathrm{LaPO}_{4} / \mathrm{LVO}$ composites, together with their high specific capacity and rate capability, make tunneled lithium vanadate promising candidate for next-generation rechargeable lithium ion batteries.

\section{Acknowledgements}

This work was partially supported by Economic, Trade and Information Commission of Shenzhen Municipality through the Graphene Manufacture Innovation Center (grant no. 201901161514), and Shenzhen Science and Technology Innovation Committee (JCYJ20151013162733704). P.P.W. and Y.D. acknowledge the support from China Postdoctoral Science Foundation with grant numbers of 2018M641823 and 2017M621287, respectively.

\section{Appendix A. Supporting information}

Supplementary data associated with this article can be found in the online version. 


\section{References:}

[1] J.B. Goodenough, K.S. Park, The Li-ion rechargeable battery: a perspective, J Am Chem Soc 135(4) (2013) 1167-76.

[2] B. Diouf, R. Pode, Potential of lithium-ion batteries in renewable energy, Renewable Energy 76 (2015) 375-380.

[3] B. Scrosati, J. Garche, Lithium batteries: Status, prospects and future, J. Power Sources 195(9) (2010) 2419-2430.

[4] F. Maroni, A. Birrozzi, G. Carbonari, F. Croce, R. Tossici, S. Passerini, F. Nobili, Graphene $/ \mathrm{V}_{2} \mathrm{O}_{5}$ Cryogel Composite As a High-Energy Cathode Material For LithiumIon Batteries, ChemElectroChem 4(3) (2017) 613-619.

[5] S. Choi, G. Wang, Advanced Lithium-Ion Batteries for Practical Applications: Technology, Development, and Future Perspectives, Adv. Mater. Technologies 3(9) (2018) 1700376.

[6] P.-P. Wang, C.-Y. Xu, L. Wang, B.-Y. Zhang, L. Zhen, Electrochemical behavior and structural stability of $\mathrm{LiV}_{3} \mathrm{O}_{8}$ microrods as cathode for lithium-ion batteries, Ceram. Int. 42(16) (2016) 18747-18755.

[7] Y. Zhao, C. Han, J. Yang, J. Su, X. Xu, S. Li, L. Xu, R. Fang, H. Jiang, X. Zou, B. Song, L. Mai, Q. Zhang, Stable alkali metal ion intercalation compounds as optimized metal oxide nanowire cathodes for lithium batteries, Nano Lett. 15(3) (2015) 2180-5. [8] P.M. Marley, G.A. Horrocks, K.E. Pelcher, S. Banerjee, Transformers: the changing phases of low-dimensional vanadium oxide bronzes, Chem. Commun. 51(25) (2015) 5181-98.

[9] N.A. Chernova, M. Roppolo, A.C. Dillon, M.S. Whittingham, Layered vanadium and molybdenum oxides: batteries and electrochromics, J. Mater. Chem. 19(17) (2009) 2526.

[10] C. Leger, S. Bach, P. Soudan, J.P. Pereira-Ramos, Structural and Electrochemical Properties of $\omega-\mathrm{Li}_{x} \mathrm{~V}_{2} \mathrm{O}_{5} \quad(0.4 \leqslant x \leqslant 3)$ as Rechargeable Cathodic Material for Lithium Batteries, J. Electrochem. Soc. 152 (2005) A236-A241.

[11] Y. Xu, X. Han, L. Zheng, W. Yan, Y. Xie, Pillar effect on cyclability enhancement 
for aqueous lithium ion batteries: a new material of $\beta$-vanadium bronze $\mathrm{M}_{0.33} \mathrm{~V}_{2} \mathrm{O}_{5}$ (M = Ag, Na) nanowires, J. Mater. Chem. 21(38) (2011) 14466.

[12] W.D. Li, C.Y. Xu, Y. Du, H.T. Fang, Y. Feng, L. Zhen, Electrochemical Lithium Insertion Behavior of $\beta-\mathrm{Li}_{x} \mathrm{~V}_{2} \mathrm{O}_{5}(0<x \leq 3)$ as the Cathode Material for Secondary Lithium Batteries, J. Electrochem. Soc. 161(1) (2014) A75-A83.

[13] N.M. Asl, J. Kim, W.C. Lee, Z. Liu, P. Lu, Y. Kim, A new chemical route for the synthesis of $\beta^{\prime}-\mathrm{Li}_{x} \mathrm{~V}_{2} \mathrm{O}_{5}$ for use as a high performance cathode, Electrochim. Acta 105 (2013) 403-411.

[14] J. Jiang, Z.X. Wang, L.Q. Chen, Structural and electrochemical studies on $\beta$ $\mathrm{Li}_{x} \mathrm{~V}_{2} \mathrm{O}_{5}$ as cathode material for rechargeable lithium batteries, J. Phys. Chem. C 111 (2007) 10707-10711.

[15] W.D. Li, C.Y. Xu, X.L. Pan, Y.D. Huang, L. Zhen, High capacity and enhanced structural reversibility of $\beta-\mathrm{Li}_{x} \mathrm{~V}_{2} \mathrm{O}_{5}$ nanorods as the lithium battery cathode, J. Mater. Chem. A 1(17) (2013) 5361-5370.

[16] R.W. Mo, F.W. Zhang, Y. Du, Z.Y. Lei, D. Rooney, K.N. Sun, Sandwich nanoarchitecture of $\mathrm{LiV}_{3} \mathrm{O}_{8}$ /graphene multilayer nanomembranes via layer-by-layer self-assembly for long-cycle-life lithium-ion battery cathodes, J. Mater. Chem. A 3(26) (2015) 13717-13723.

[17] Y. Wang, G.Z. Cao, Synthesis and Enhanced Intercalation Properties of Nanostructured Vanadium Oxides, Chem. Mater. (18) (2006) 2787-2804.

[18] H.Q. Song, M.S. Luo, A.M. Wang, High Rate and Stable Li-Ion Insertion in Oxygen-Deficient $\mathrm{LiV}_{3} \mathrm{O}_{8}$ Nanosheets as a Cathode Material for Lithium-Ion Battery, ACS Appl. Mater. Interfaces 9(3) (2017) 2875-2882.

[19] K.X. Wang, X.H. Li, J.S. Chen, Surface and interface engineering of electrode materials for lithium-ion batteries, Adv. Mater. 27(3) (2015) 527-45.

[20] Y.K. Lu, J. Wu, J. Liu, M. Lei, S.S. Tang, P.J. Lu, L.Y. Yang, H.R. Yang, Q. Yang, Facile Synthesis of $\mathrm{Na}_{0.33} \mathrm{~V}_{2} \mathrm{O}_{5}$ Nanosheet-Graphene Hybrids as Ultrahigh Performance Cathode Materials for Lithium Ion Batteries, ACS Appl. Mater. Interfaces 7(31) (2015) 17433-40.

[21] R.W. Mo, Y. Du, N.Q. Zhang, D. Rooney, K.N. Sun, In situ synthesis of $\mathrm{LiV}_{3} \mathrm{O}_{8}$ 
nanorods on graphene as high rate-performance cathode materials for rechargeable lithium batteries, Chem. Commun. 49(80) (2013) 9143-5.

[22] H.Y. Kang, Y.C. Liu, M.H. Shang, T.Y. Lu, Y.J. Wang, L.F. Jiao, $\mathrm{NaV}_{3} \mathrm{O}_{8}$ nanosheet@polypyrrole core-shell composites with good electrochemical performance as cathodes for Na-ion batteries, Nanoscale 7(20) (2015) 9261-9267.

[23] H.P. Guo, L. Liu, Q.L. Wei, H.B. Shu, X.K. Yang, Z.H. Yang, M. Zhou, J.L. Tan, Z.C. Yan, X.Y. Wang, Electrochemical characterization of polyaniline- $\mathrm{LiV}_{3} \mathrm{O}_{8}$ nanocomposite cathode material for lithium ion batteries, Electrochim. Acta 94 (2013) 113-123.

[24] L.F. Jiao, L. Liu, J. Sun, L. Yang, Y.H. Zhang, H.T. Yuan, Y.M. Wang, X.D. Zhou, Effect of $\mathrm{AlPO}_{4}$ Nanowire Coating on the Electrochemical Properties of $\mathrm{LiV}_{3} \mathrm{O}_{8}$ Cathode Material, J. Phys. Chem. C 112 (2008) 18249-18254.

[25] R.W. Mo, Y. Du, N.Q. Zhang, D. Rooney, K.N. Sun, Surface modification of $\mathrm{LiV}_{3} \mathrm{O}_{8}$ nanosheets via layer-by-layer self-assembly for high-performance rechargeable lithium batteries, J. Power Sources 257 (2014) 319-324.

[26] S. Huang, J.P. Tu, X.M. Jian, Y. Lu, S.J. Shi, X.Y. Zhao, T.Q. Wang, X.L. Wang, C.D. $\mathrm{Gu}$, Enhanced electrochemical properties of $\mathrm{Al}_{2} \mathrm{O}_{3}$-coated $\mathrm{LiV}_{3} \mathrm{O}_{8}$ cathode materials for high-power lithium-ion batteries, Journal of Power Sources 245 (2014) 698-705.

[27] Y.Y. Shao, J. Wang, M. Engelhard, C.M. Wang, Y.H. Lin, Facile and controllable electrochemical reduction of graphene oxide and its applications, J. Mater. Chem. 20(4) (2010) 743-748.

[28] W. Zhang, P.J. Zuo, C. Chen, Y.L. Ma, X.Q. Cheng, C.Y. Du, Y.Z. Gao, G.P. Yin, Facile synthesis of binder-free reduced graphene oxide/silicon anode for highperformance lithium ion batteries, J. Power Sources 312 (2016) 216-222.

[29] J. Bao, M. Zhou, Y.Q. Zeng, L.F. Bai, X.D. Zhang, K. Xu, Y. Xie, $\mathrm{Li}_{0.3} \mathrm{~V}_{2} \mathrm{O}_{5}$ with high lithium diffusion rate: a promising anode material for aqueous lithium-ion batteries with superior rate performance, J. Mater. Chem. A 1(17) (2013) 5423-5429. [30] R. Baddour-Hadjean, S. Bach, N. Emery, J.P. Pereira-Ramos, The peculiar structural behaviour of $\beta-\mathrm{Na}_{0.33} \mathrm{~V}_{2} \mathrm{O}_{5}$ upon electrochemical lithium insertion, J. Mater. 
Chem. 21(30) (2011) 11296.

[31] J.T. Xu, M. Wang, N.P. Wickramaratne, M. Jaroniec, S.X. Dou, L.M. Dai, Highperformance sodium ion batteries based on a 3D anode from nitrogen-doped graphene foams, Adv. Mater. 27(12) (2015) 2042-2048.

[32] P.P. Wang, C.Y. Xu, F.X. Ma, L. Yang, L. Zhen, In situ soft-chemistry synthesis of $\beta-\mathrm{Na}_{0.33} \mathrm{~V}_{2} \mathrm{O}_{5}$ nanorods as high-performance cathode for lithium-ion batteries, RSC Adv. 6(107) (2016) 105833-105839.

[33] H. Song, M. Luo, A. Wang, High Rate and Stable Li-Ion Insertion in OxygenDeficient $\mathrm{LiV}_{3} \mathrm{O}_{8}$ Nanosheets as a Cathode Material for Lithium-Ion Battery, ACS Appl Mater Interfaces 9(3) (2017) 2875-2882.

[34] M.L. Li, L.X. Zhang, X.Q. Fan, M.Y. Wu, M. Wang, R.L. Cheng, L.L. Zhang, H.L. Yao, S.J. Lin, Core-shell $\mathrm{LaPO}_{4} / \mathrm{g}-\mathrm{C}_{3} \mathrm{~N}_{4}$ nanowires for highly active and selective CO 2 reduction, Appl. Catal. B-Environ. 201 (2017) 629-635.

[35] J. Kawakita, M. Majima, T. Miura, T. Kishi, Preparation and lithium insertion behaviour of oxygen-deficient $\mathrm{Li}_{1+{ }_{x}} \mathrm{~V}_{3} \mathrm{O}_{8-}$. . J. Power Sources 66 (1997) 135-139.

[36] J.L. Cheng, B. Wang, H.L. Xin, G.C. Yang, H.Q. Cai, F.D. Nie, H. Huang, Selfassembled $\mathrm{V}_{2} \mathrm{O}_{5}$ nanosheets_reduced graphene oxide hierarchical nanocomposite as a high-performance cathode material for lithium ion batteries, J. Mater. Chem. A 1 (2013) 10814-10820.

[37] Y.L. Zhao, J.G. Feng, X. Liu, F.C. Wang, L.F. Wang, C.W. Shi, L. Huang, X. Feng, X.Y. Chen, L. Xu, M.Y. Yan, Q.J. Zhang, X.D. Bai, H.G. Wu, L.Q. Mai, Selfadaptive strain-relaxation optimization for high-energy lithium storage material through crumpling of graphene, Nat. Commun. 5 (2014) 4565.

[38] A.D. Wadsley, The crystal structure of $\mathrm{Na}_{2-x} \mathrm{~V}_{6} \mathrm{O}_{15}$, Acta Cryst. 8 (1955) 695-701. [39] J.D. J. Galy, A. Casalot, J. B. Goodenough, Structure of the $\mathrm{M}_{x} \mathrm{~V}_{2} \mathrm{O}_{5-\beta}$ and $\mathrm{M}_{x} \mathrm{~V}_{2-}$ ${ }_{y} \mathrm{TyO}_{5-\beta}$ Phases, J. Solid State Chem. 1 (1970) 339-348.

[40] X. Sun, C.G. Zhou, M. Xie, T. Hu, H.T. Sun, G.Q. Xin, G.K. Wang, S.M. Georgec, J. Lian, Amorphous vanadium oxide coating on graphene by atomic layer deposition for stable high energy lithium ion anodes, Chem. Commun. 50(73) (2014) 10703-10706. 
[41] R. Mo, F. Zhang, Y. Du, Z. Lei, D. Rooney, K. Sun, Sandwich nanoarchitecture of $\mathrm{LiV}_{3} \mathrm{O}_{8}$ /graphene multilayer nanomembranes via layer-by-layer self-assembly for long-cycle-life lithium-ion battery cathodes, J. Mater. Chem. A 3(26) (2015) 1371713723.

[42] K. West, B. Zachau-Christiansen, T. Jacobsen, S. Skaarup, Lithium insertion into vanadium pentoxide bronzes, Solid State Ionics (76) (1995) 15-21.

[43] A. Sakunthala, M.V. Reddy, S. Selvasekarapandian, B.V.R. Chowdari, P.C. Selvind, Energy storage studies of bare and doped vanadium pentoxide, $\left(V_{1.95} M_{0.05}\right) \mathrm{O}_{5}$, $M=$ Nb, Ta, for lithium ion batteries, Energ. Environ. Sci. 4 (2011) 1712-1725.

[44] B. Yan, M.S. Li, X.F. Li, Z.M. Bai, L. Dong, D.J. Li, Electrochemical Impedance Spectroscopy Illuminating Performance Evolution of Porous Core-Shell Structured Nickel_Nickel Oxide Anode Materials, Electrochim. Acta 164 (2015) 55-61.

[45] F. Gao, Z.Y. Tang, Kinetic behavior of $\mathrm{LiFePO}_{4} / \mathrm{C}$ cathode material for lithiumion batteries, Electrochim. Acta 53(15) (2008) 5071-5075.

[46] Z. Ma, Y. Peng, G. Wang, Y. Fan, J. Song, T. Liu, X. Qin, G. Shao, Enhancement of electrochemical performance for $\mathrm{LiFePO} 4$ cathodes via hybrid coating with electron conductor carbon and lithium ion conductor LaPO4, Electrochim. Acta 156 (2015) 77-85. 


\section{Figures and Captions:}

Figure 1 Crystal structure and morphology characterization. (a, b) Crystal structure of $\beta$ - $\mathrm{Li}_{x} \mathrm{~V}_{2} \mathrm{O}_{5}$ with different projections along $b$ and $a$-axis, respectively. V1 represent the edge-sharing $\mathrm{VO}_{6}$ octahedra, $\mathrm{V} 2$ represents the corner-sharing $\mathrm{VO}_{6}$ octahedra, and V3 represents the $\mathrm{VO}_{5}$ pyramids. (c) XRD patterns of $\mathrm{LVO}, \mathrm{LaPO}_{4} / \mathrm{LVO}$ and $\mathrm{rGO} / \mathrm{LaPO}_{4} / \mathrm{LVO}$. The standard patterns of $\mathrm{Li}_{0.33} \mathrm{~V}_{2} \mathrm{O}_{5}$ is shown in the lower panel. (d) SEM, (e) TEM and (f) HRTEM images of $\mathrm{LaPO}_{4}$-coated LVO nanorods wrapped by rGO nanosheets. Inset in (e) is enlarged view of the interface.

Figure 2 XPS spectra of $\mathrm{LVO}, \mathrm{LaPO}_{4} / \mathrm{LVO}$ and $\mathrm{rGO} / \mathrm{LaPO}_{4} / \mathrm{LVO}$. (a) Survey spectra; (b) V2p; (c) core-level XPS spectra of La3d.

Figure 3 Electrochemical performance of $\mathrm{LVO}$ and $\mathrm{rGO} / \mathrm{LaPO}_{4} / \mathrm{LVO}$ electrodes. (a) CV curves at scan rate of $0.05 \mathrm{mV} \mathrm{s}^{-1}$. (b) Charge/discharge curves of LVO electrode.

(c) Charge/discharge curves of $\mathrm{rGO} / \mathrm{LaPO}_{4} / \mathrm{LVO}$ electrode. (d) Crystal structure of $\beta$ $\mathrm{Li}_{x} \mathrm{~V}_{2} \mathrm{O}_{5}$ with four possible tunnel sites for the inserted $\mathrm{Li}^{+}$in the $\beta$ structure marked with different colors. (e) Cycling performance at current density of $60 \mathrm{~mA} \mathrm{~g}^{-1}$. (f) Rate capability at current densities of 15 to $400 \mathrm{~mA} \mathrm{~g}^{-1}$.

Figure 4 Electrochemical impedance spectrum analysis before and after 100 cycles. (a) Nyquist plots of $\mathrm{LVO}$ and $\mathrm{rGO} / \mathrm{LaPO}_{4} / \mathrm{LVO}$ electrodes after initial cycles. Inset is the equivalent circuit for EIS fitting. (b) Nyquist plots of LVO and rGO/LaPO $4 / \mathrm{LVO}$ electrodes after 100 cycles. (c) The relationship between $Z^{\prime}$ and $\omega^{-1 / 2}$ in the lowfrequency range. (d) Differential capacity $(\mathrm{d} Q / \mathrm{d} V)$ curves of LVO and $\mathrm{rGO} / \mathrm{LaPO}_{4} / \mathrm{LVO}$ electrodes after 100 cycles.

Figure 5 Structural and morphology characterization of LVO electrode upon cycling. (a) XRD pattern with magnified patterns of the $\mathrm{LVO}$ and $\mathrm{rGO} / \mathrm{LaPO}_{4} / \mathrm{LVO}$ electrodes after 100 cycles. (b) and (c) SEM images of the LVO electrodes before and after 100 
cycles. (d) and (e) SEM images of the $\mathrm{rGO} / \mathrm{LaPO}_{4} / \mathrm{LVO}$ electrode before and after 100 cycles.

Figure 6 The interfacial schematic diagram of LVO electrode with rGO and $\mathrm{LaPO}_{4}$ layer, which provide effective electronic transport path and protect electrode surface from electrolyte corrosion. 

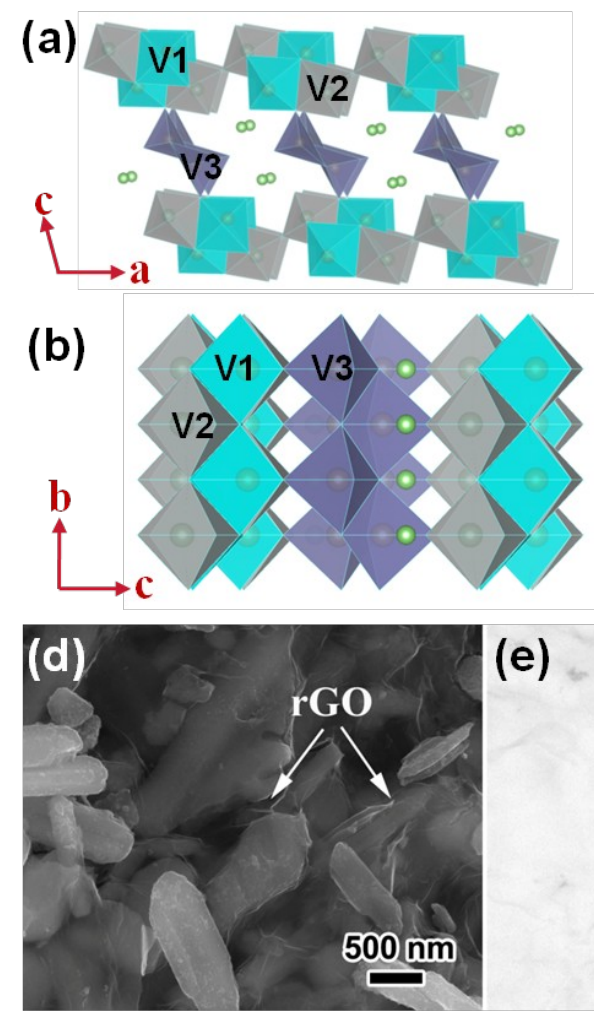

(e)
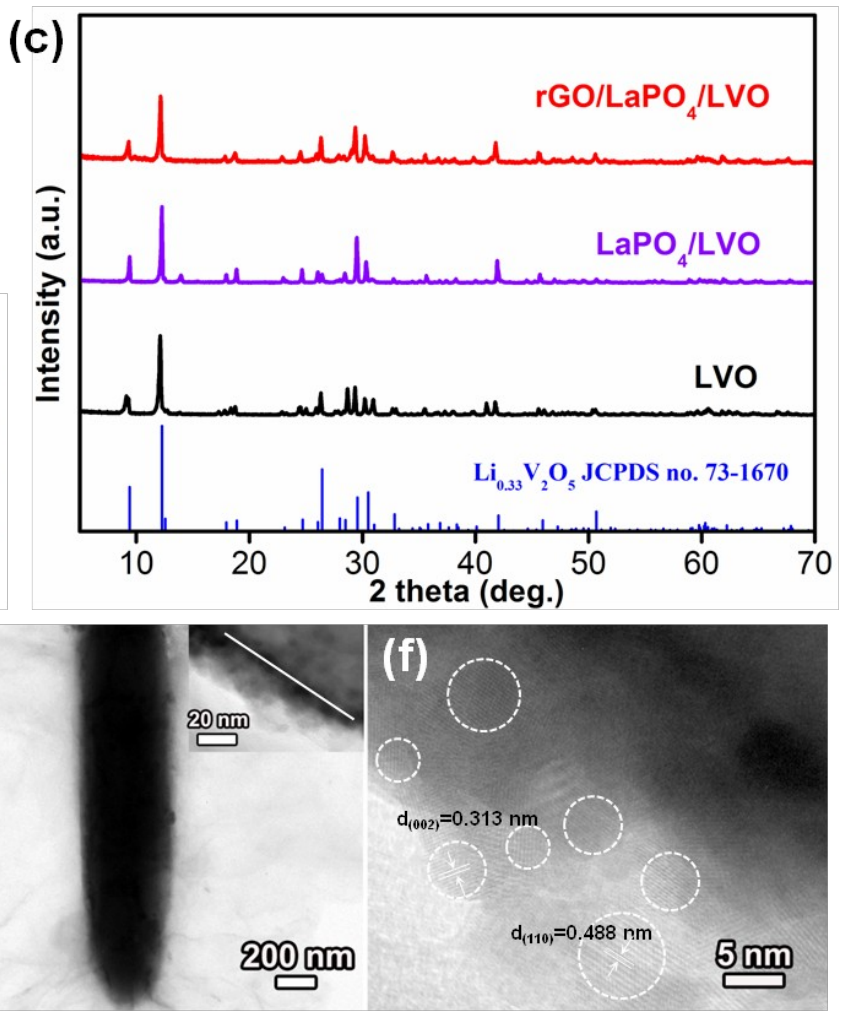

Figure 1 Crystal structure and morphology characterization. (a, b) Crystal structure of $\beta-\mathrm{Li}_{x} \mathrm{~V}_{2} \mathrm{O}_{5}$ with different projections along $b$ and $a$-axis, respectively. V1 represent the edge-sharing $\mathrm{VO}_{6}$ octahedra, V2 represents the corner-sharing $\mathrm{VO}_{6}$ octahedra, and V3 represents the $\mathrm{VO}_{5}$ pyramids. (c) XRD patterns of $\mathrm{LVO}, \mathrm{LaPO}_{4} / \mathrm{LVO}$ and $\mathrm{rGO} / \mathrm{LaPO}_{4} / \mathrm{LVO}$. The standard patterns of $\mathrm{Li}_{0.33} \mathrm{~V}_{2} \mathrm{O}_{5}$ is shown in the lower panel. (d) SEM, (e) TEM and (f) HRTEM images of $\mathrm{LaPO}_{4}$-coated LVO nanorods wrapped by rGO nanosheets. Inset in (e) is enlarged view of the interface.
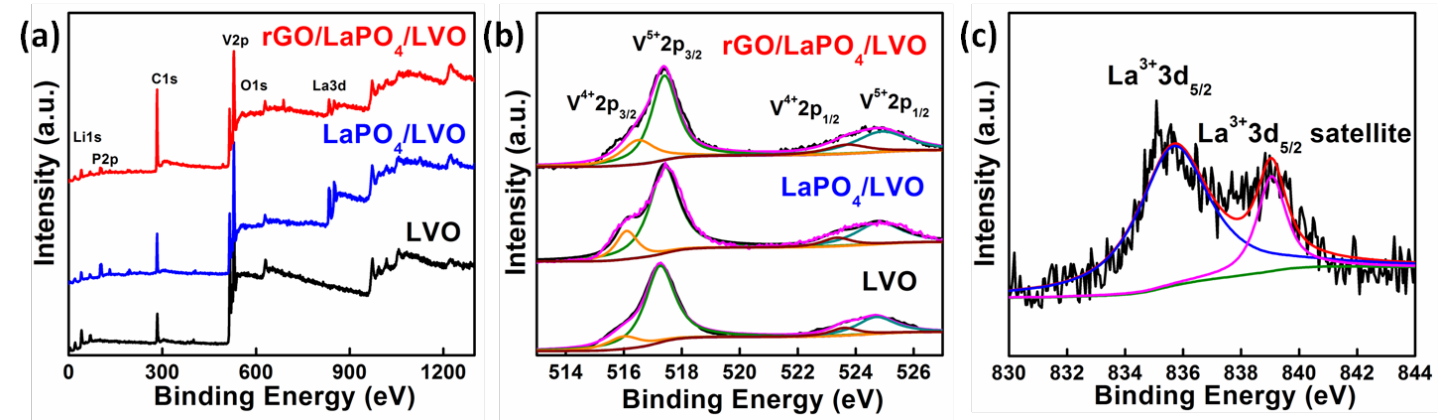

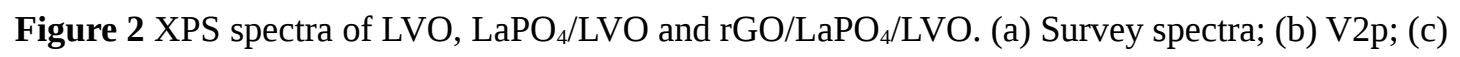
core-level XPS spectra of La3d. 

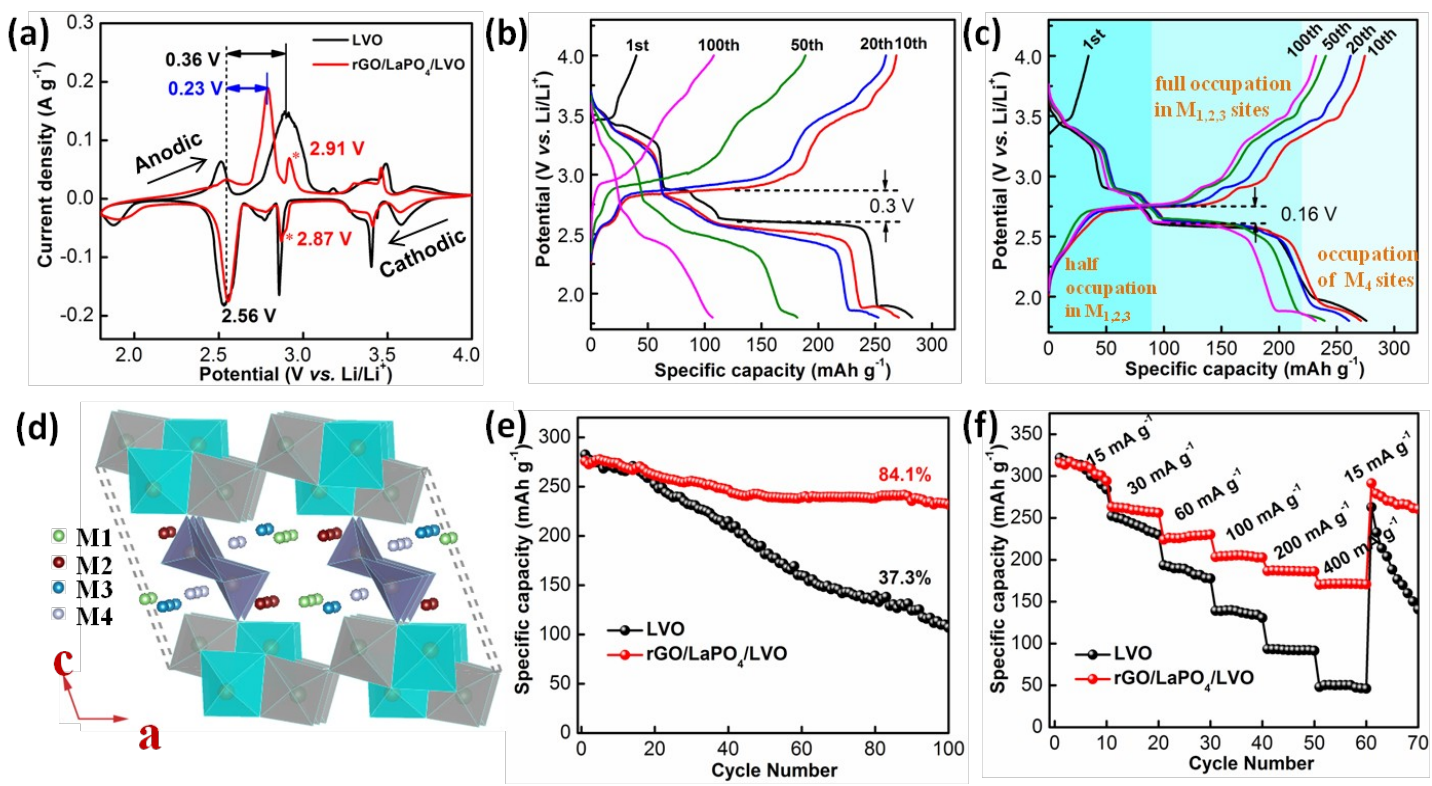

Figure 3 Electrochemical performance of $\mathrm{LVO}$ and $\mathrm{rGO} / \mathrm{LaPO}_{4} / \mathrm{LVO}$ electrodes. (a) $\mathrm{CV}$ curves at scan rate of $0.05 \mathrm{mV} \mathrm{s}^{-1}$. (b) Charge/discharge curves of LVO electrode. (c) Charge/discharge curves of $\mathrm{rGO} / \mathrm{LaPO}_{4} / \mathrm{LVO}$ electrode. (d) Crystal structure of $\beta-\mathrm{Li}_{x} \mathrm{~V}_{2} \mathrm{O}_{5}$ with four possible tunnel sites for the inserted $\mathrm{Li}^{+}$in the $\beta$ structure marked with different colors. (e) Cycling performance at current density of $60 \mathrm{~mA} \mathrm{~g}^{-1}$. (f) Rate capability at current densities of 15 to $400 \mathrm{~mA} \mathrm{~g}^{-1}$. 

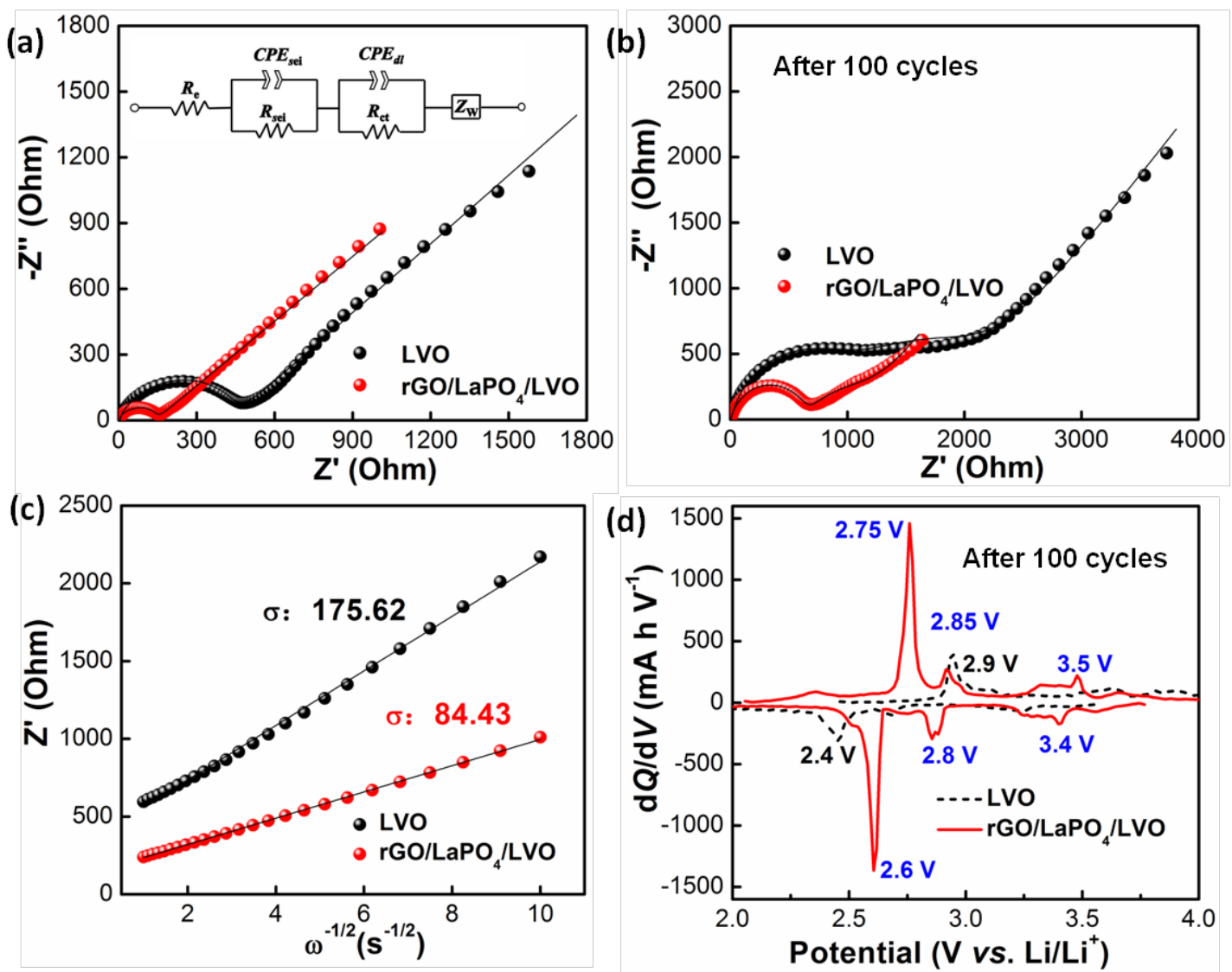

Figure 4 Electrochemical impedance spectrum analysis before and after 100 cycles. (a) Nyquist plots of $\mathrm{LVO}$ and $\mathrm{rGO} / \mathrm{LaPO}_{4} / \mathrm{LVO}$ electrodes after initial cycles. Inset is the equivalent circuit for EIS fitting. (b) Nyquist plots of $\mathrm{LVO}$ and $\mathrm{rGO} / \mathrm{LaPO}_{4} / \mathrm{LVO}$ electrodes after 100 cycles. (c) The relationship between $Z^{\prime}$ and $\omega^{-1 / 2}$ in the low-frequency range. (d) Differential capacity (dQ/dV) curves of $\mathrm{LVO}$ and $\mathrm{rGO} / \mathrm{LaPO}_{4} / \mathrm{LVO}$ electrodes after 100 cycles. 

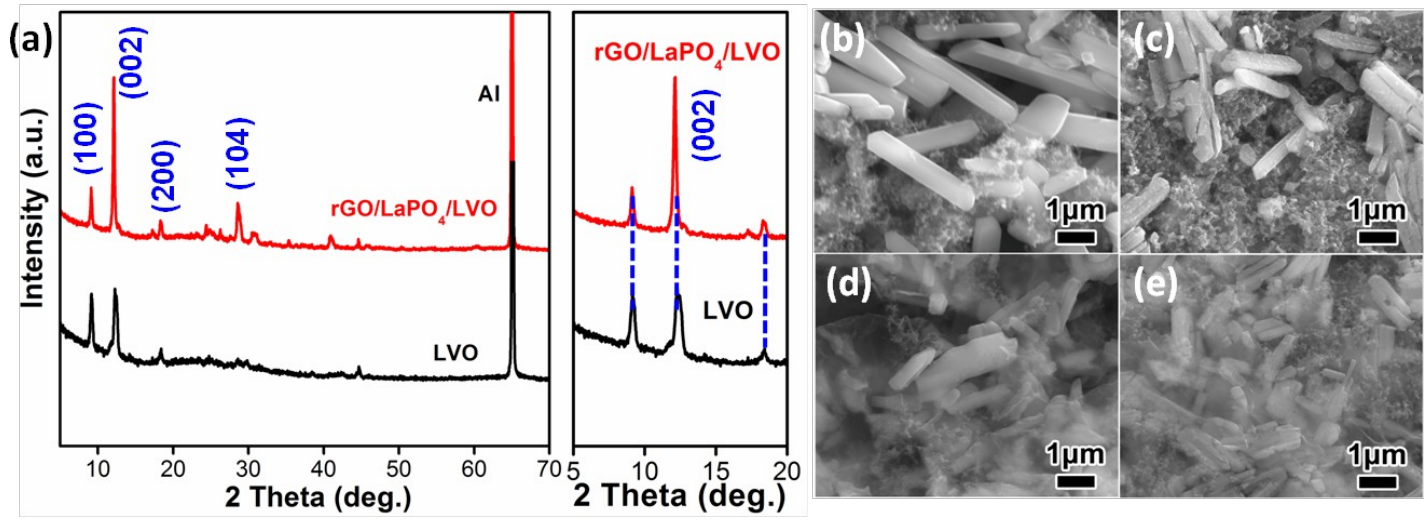

Figure 5 Structural and morphology characterization of LVO electrode upon cycling. (a) XRD pattern with magnified patterns of the $\mathrm{LVO}$ and $\mathrm{rGO} / \mathrm{LaPO}_{4} / \mathrm{LVO}$ electrodes after 100 cycles. (b) and (c) SEM images of the LVO electrodes before and after 100 cycles. (d) and (e) SEM images of the $\mathrm{rGO} / \mathrm{LaPO}_{4} / \mathrm{LVO}$ electrode before and after 100 cycles.

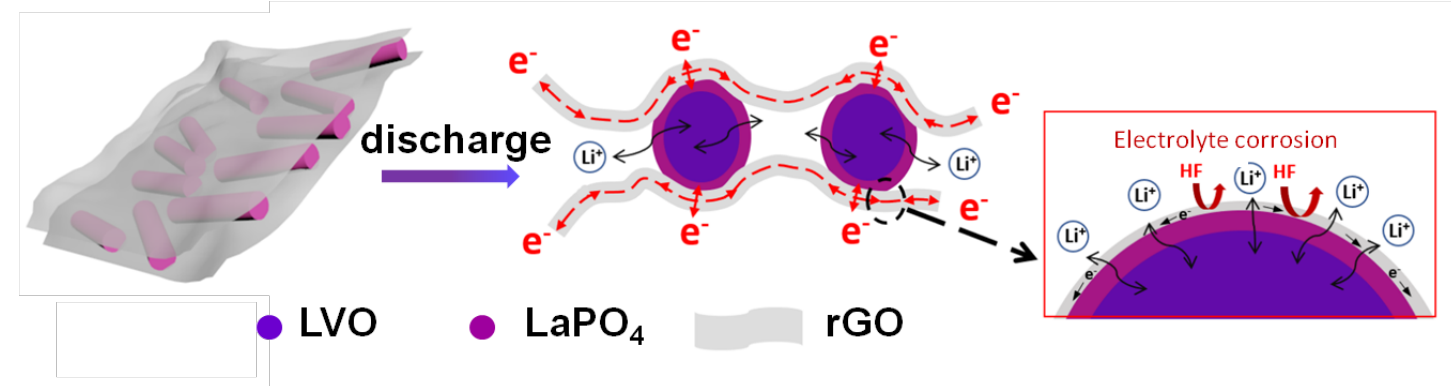

Figure 6 The interfacial schematic diagram of LVO electrode with rGO and $\mathrm{LaPO}_{4}$ layer, which provide effective electronic transport path and protect electrode surface from electrolyte corrosion. 
Table 1. EIS fitting data of $\mathrm{LVO}$ and $\mathrm{rGO} / \mathrm{LaPO}_{4} / \mathrm{LVO}$ after $1^{\text {st }}$ and $100^{\text {th }}$ cycles

\begin{tabular}{ccccc}
\hline \multirow{2}{*}{ Cycles } & $\mathrm{LVO}$ & $\mathrm{LVO}$ & $\mathrm{rGO} / \mathrm{LaPO}_{4} / \mathrm{LVO}$ & $\mathrm{rGO} / \mathrm{LaPO}_{4} / \mathrm{LVO}$ \\
& $R_{\text {sei }} / \Omega$ & $R_{\mathrm{ct}} / \Omega$ & $R_{\text {sei }} / \Omega$ & $R_{\mathrm{ct}} / \Omega$ \\
\hline \multirow{2}{*}{$1 \mathrm{st}$} & 45.5 & 379.8 & 37.4 & 98.2 \\
\multirow{2}{*}{100 th } & 963.2 & 970.2 & 555.8 & 634.5 \\
\hline
\end{tabular}




\section{Boosting the rate and cycling performance of $\beta$ - $\mathrm{Li}_{x} \mathrm{~V}_{2} \mathrm{O}_{5}$}

\section{nanorods for Li ion battery by electrode surface decoration}

Pan-Pan Wang ${ }^{\mathrm{a}, \mathrm{b}, \mathrm{c}}$, Yue Du ${ }^{\mathrm{a}, \mathrm{c}}$, Bao-You Zhang ${ }^{\mathrm{b}}$, Yan-Xin Yao ${ }^{\mathrm{b}}$, Yu-Chen Xiao ${ }^{\mathrm{b}}, \mathrm{Li}$-Jie

$\mathrm{Ci}^{\mathrm{a}}$, Cheng-Yan $\mathrm{Xu}^{\mathrm{a}, \mathrm{b}, \mathrm{c}, *}$, Liang Zhen ${ }^{\mathrm{a}, \mathrm{b}, \mathrm{c}, *}$

${ }^{a}$ School of Materials Science and Engineering, Harbin Institute of Technology (Shenzhen), Shenzhen 518055, China

${ }^{b}$ School of Materials Science and Engineering, Harbin Institute of Technology, Harbin 150001, China

${ }^{c}$ MOE Key Laboratory of Micro-Systems and Micro-Structures Manufacturing, Harbin Institute of Technology, Harbin 150080, China

E-mail: lzhen@hit.edu.cn (L.Z.); cy_xu@hit.edu.cn (C.Y.X.)

Abstract: The $\beta$-phase lithium vanadium oxide bronze $\left(\beta-\mathrm{Li}_{x} \mathrm{~V}_{2} \mathrm{O}_{5}\right)$ with high theoretic specific capacity up to $440 \mathrm{mAh} \mathrm{g}^{-1}$ is considered as promising cathode materials, however, their practical application is hindered by its poor ionic and electronic conductivity, resulting in unsatisfied cyclic stability and rate capability. Herein, we report the surface decoration of $\beta-\mathrm{Li}_{x} \mathrm{~V}_{2} \mathrm{O}_{5}$ cathode using both reduced oxide graphene and ionic conductor $\mathrm{LaPO}_{4}$, which significantly promotes the electronic transfer and $\mathrm{Li}^{+}$diffusion rate, respectively. As a result, the $\mathrm{rGO} / \mathrm{LaPO}_{4} / \mathrm{Li}_{x} \mathrm{~V}_{2} \mathrm{O}_{5}$ composite exhibits excellent electrochemical performance in terms of high reversible specific capacity of $275.7 \mathrm{mAh} \mathrm{g}^{-1}$ with high capacity retention of $84.1 \%$ after 100 cycles at a current density of $60 \mathrm{~mA} \mathrm{~g}^{-1}$, and acceptable 
specific capacity of $170.3 \mathrm{mAh} \mathrm{g}^{-1}$ at high current density of $400 \mathrm{~mA} \mathrm{~g}^{-1}$. The cycled electrode is also analyzed by electrochemical impedance spectroscopy, ex-situ X-ray diffraction and scanning electron microscope, providing further insights into the improvement of electrochemical performance. Our results provide an effective approach to boost the electrochemical properties of lithium vanadates for practical application in lithium ion batteries.

Keywords: $\beta$ - $\mathrm{Li}_{x} \mathrm{~V}_{2} \mathrm{O}_{5}$, cyclic stability, reduced oxide graphene, ionic conductor, surface decoration

\section{Introduction}

Due to the attractive merits of high energy density, long cyclic life and environmental friendliness, rechargeable lithium ion batteries (LIBs) have been widely used as power source for portable electronic devices.[1-3] Despite that, the energy and power density of current commercial LIBs was still far from satisfying the urgent requirements for further applications in electric vehicles and smart grids. The limited capacity of commonly used cathodes, including $\mathrm{LiCoO}_{2}, \mathrm{LiFePO}_{4}, \mathrm{LiMn}_{2} \mathrm{O}_{4}$ and $\mathrm{Li}$-excess layered oxide compounds, is the main limiting factor for the realization of high energy-density LIBs, which delivered lower reversible capacities $\left(<280 \mathrm{mAh} \mathrm{g}^{-1}\right)$ than the counterpart graphite anode. To this end, cathode material with higher specific capacity are urgently needed to meet the ever-increasing goals for high energy-density LIBs. $[4,5]$

Recently, vanadium oxides and their derivatives have received tremendous attention due to their rich chemistry and high specific capacity as LIBs 
cathode.[6-8] As for $\mathrm{V}_{2} \mathrm{O}_{5}$, its theoretical capacity reaches up to $440 \mathrm{mAh} \mathrm{g}^{-1}$ because more than 3 lithium ions per formula can be inserted into $\mathrm{V}_{2} \mathrm{O}_{5}$ layer, whereas the capacity of $\mathrm{V}_{2} \mathrm{O}_{5}$ cathode decays seriously after initial cycling due to the irreversible phase transformation and local structure collapse when the lithium uptakes more than 2 moles per formula unit.[9, 10] Different from layered $\mathrm{V}_{2} \mathrm{O}_{5}, \beta$-phase vanadium oxide bronzes $\left(\beta-\mathrm{M}_{x} \mathrm{~V}_{2} \mathrm{O}_{5}, \mathrm{M}=\right.$ alkali, alkaline earth, and transition metals) adopts more stable and rigid crystal structures with the $\left[\mathrm{VO}_{6}\right]$ octahedrons layers pillared by $\left[\mathrm{VO}_{5}\right]$ square pyramids.[11] The unique 3D framework contained several feasible interstitial sites in the tunnel structure, endowing the vanadium oxide bronzes rather good structural reversibility upon large amount of lithium accommodation, while maintaining high capacity features. [12-15] Despite these advantages, one major drawback of pure $\beta$-phase vanadate cathode is its inferior rate capability and cycling stability,[16, 17] which was believed to be related with its intrinsic poor electronic conductivity and relatively slow $\mathrm{Li}^{+}$diffusion kinetic, especially upon deep lithiation. Meanwhile, the fragile interfacial property of pristine vanadate electrode with the risk of erosion from the electrolytes and vanadium dissolution is considered to be another reason for capacity fading.[18] Thus, modification strategies are imperative to overcome these limitations, thereby boosting the electrochemical properties of lithium vanadate cathode.[19]

Surface modification with conducting materials (e.g., graphene,[20, 21] polymer,[22, 23]) or ionic conductors (phosphates,[24] metal oxides,[25, 26] 
etc.) is proved to be efficient to enhance the electrochemical properties of vanadate oxide cathode. Recently, two-dimensional graphene-based materials were emerging as an eye-catching coating candidate with superior electrical conductivity, which was usually hybrid with active materials through hydrothermal route or calcination treatment in reductive atmosphere. Whereas the coexisted $\mathrm{V}^{4+}$ and $\mathrm{V}^{5+}$ in $\beta-\mathrm{Li}_{x} \mathrm{~V}_{2} \mathrm{O}_{5}$ are susceptible to the reductive graphene during the hybridization process especially under high calcination temperature, resulting in undesired impurity phase or even inducing irreversible phase transition and thus capacity loss of the cathode. To achieve a uniform graphene coating layer on $\beta-\mathrm{Li}_{x} \mathrm{~V}_{2} \mathrm{O}_{5}$ with complex valence states while maintain the $\beta-\mathrm{Li}_{x} \mathrm{~V}_{2} \mathrm{O}_{5}$ phase is still a big challenge. Herein, a gentle freeze drying strategy with ionic conductor decoration was applied successfully to tackle these issues.

In this work, the conductive reduced oxide graphene (rGO) and ionic conductor $\mathrm{LaPO}_{4}$ were employed to engineer the interfacial chemistry of $\beta-\mathrm{Li}_{x} \mathrm{~V}_{2} \mathrm{O}_{5}$ cathode via chemical precipitation route followed by frozen dryness. The obtained $\mathrm{rGO} / \mathrm{LaPO}_{4} / \mathrm{LVO}$ electrode demonstrated remarkable cycling stability and superior rate capability with specific $\mathrm{Li}^{+}$multiple-insertion mechanism, which was attributed to the assistance of conductive rGO and ionic conductor $\mathrm{LaPO}_{4}$ layer, with the ability to promote electronic transfer and $\mathrm{Li}^{+}$ diffusion coefficient between active nanorods efficiently.

\section{Experimental section}




\subsection{Synthesis of $\beta-\mathrm{Li}_{x} \mathrm{~V}_{2} \mathrm{O}_{5}$ nanorods}

The $\beta-\mathrm{Li}_{x} \mathrm{~V}_{2} \mathrm{O}_{5}$ nanorods were obtained by a facile hydrothermal route followed by calcination treatment.[15] Briefly, $0.1 \mathrm{~g} \mathrm{~V}_{2} \mathrm{O}_{5}$ and $3.0 \mathrm{~g} \mathrm{LiNO}_{3}$ were added into $30 \mathrm{~mL}$ de-ionized water with vigorously stirring. Then, the orange-yellow suspension was transferred into $50 \mathrm{~mL}$ Teflon-lined stainless autoclave and heated at $220^{\circ} \mathrm{C}$ for $24 \mathrm{~h}$. The precursor was collected by centrifugation and washed with absolute ethanol for several times, which was calcinated at $600{ }^{\circ} \mathrm{C}$ for $3 \mathrm{~h}$ under $\mathrm{Ar}$ atmosphere. The final product was denoted as LVO.

\section{2 $\mathrm{LaPO}_{4}$ coating and $r G O$ wrapping}

The surface modification of $\beta-\mathrm{Li}_{x} \mathrm{~V}_{2} \mathrm{O}_{5}$ nanorods was implemented by a two-step process involving chemical precipitation and frozen dryness. Firstly, $90 \mathrm{mg}$ LVO powder was dispersed into $0.1 \mathrm{M} \mathrm{La}\left(\mathrm{NO}_{3}\right)_{3} \cdot 6 \mathrm{H}_{2} \mathrm{O}$ (Aldrich, 99.99\%) and $\mathrm{NH}_{4} \mathrm{H}_{2} \mathrm{PO}_{4}$ solution with continuous stirring for $24 \mathrm{~h}$, which was evaporated at room temperature and calcinated at $400{ }^{\circ} \mathrm{C}$ for $3 \mathrm{~h}$ under Ar atmosphere. The corresponding products were denoted as $\mathrm{LaPO}_{4} / \mathrm{LVO}$. Subsequently, the obtained $\mathrm{LaPO}_{4} / \mathrm{LVO}$ powder was dispersed into $20 \mathrm{~mL} 0.5 \mathrm{M}$ rGO solution by vigorous stirring, which was frozen quickly by liquid nitrogen and frozen dried overnight. The final product was obtained with heat treatment at $180{ }^{\circ} \mathrm{C}$ for $2 \mathrm{~h}$ under $\mathrm{Ar}$ atmosphere and labeled as $\mathrm{rGO} / \mathrm{LaPO}_{4} / \mathrm{LVO}$. Herein, the $\mathrm{rGO}$ nanosheets were prepared from natural graphite powders by Hummer's method.[27, 28]

\subsection{Characterization of morphology and structure}

The crystal structure of the obtained products was performed by X-ray diffraction 
(XRD, Rigaku D/Max2500 with $\mathrm{Cu} \mathrm{K}_{\alpha}$ radiation) and Raman spectra (Jobin Yvon Horiba with He-Ne laser, $632.9 \mathrm{~nm}$ ). The morphology characterization was collected by field-emission scanning electron microscope (FE-SEM, FEI Quanta 200F), and transmission electron microscope (TEM, JEM 2100, $200 \mathrm{kV}$ ), respectively. The chemical valence was analyzed by X-ray photoelectron spectroscopy (XPS, ThermoFisher). The binding energy of XPS was corrected by adjusting the C 1s photoelectron peak at $284.8 \mathrm{eV}$ for the reference.

\subsection{Electrochemical measurements}

The electrochemical performance of $\beta-\mathrm{Li}_{x} \mathrm{~V}_{2} \mathrm{O}_{5}$ electrode before and after surface modification was evaluated using CR2025-type coin cells, which were assembled in an Ar-filled glovebox (Germany, MBraun) with the contents of $\mathrm{H}_{2} \mathrm{O}$ and $\mathrm{O}_{2}$ less than $5 \mathrm{ppm}$. The cathode was fabricated by mixing the active material, conductive agent and PVDF binder in the weight ratios of $8: 1: 1$ and pasted onto Al foils, which was punched into round disk with diameter of $14 \mathrm{~mm}$ after vacuum dryness. $1 \mathrm{M} \mathrm{LiPF}_{6}$ dissolved in ethylene carbonate/ethyl methyl carbonate/dimethylcarbonate (EC/EMC/DMC $1: 1: 1$ in volume ratio) solvent was adopted as the electrolyte. The lithium metal was employed as the counter/reference electrode and the porous polypropylene films were served as separator, respectively.

The charge/discharge tests were carried out on LAND multi-channel battery testing system (CT2001A, Jinnuo Wuhan Corp., China) in the potential range of 1.8-4.0 V (vs. $\left.\mathrm{Li} / \mathrm{Li}^{+}\right)$. Both cyclic voltammetry (CV) and electrochemical impedance spectroscopy (EIS) tests were operated on electrochemical workstation (CHI660E). 
The scan rate of $\mathrm{CV}$ was set as $0.05 \mathrm{mV} \mathrm{s}^{-1}$ and the frequency of EIS ranged from 100 $\mathrm{kHz}$ to $0.01 \mathrm{~Hz}$, respectively. For the SEM and XRD test of the cycled electrode, the coin cells were disassembled in Ar-filled glove box and rinsed in DMC solvent repeatedly.

\section{Results and discussion}

\subsection{Characterization of $r G O / \mathrm{LaPO}_{4} / \mathrm{LVO}$ nanorods}

In the crystal structure of $\beta-\mathrm{Li}_{x} \mathrm{~V}_{2} \mathrm{O}_{5}$ (Figure 1a), there are three different vanadium sites marked with different colours, namely, $\mathrm{V}(1), \mathrm{V}(2)$, and $\mathrm{V}(3)$. The edge-sharing $\mathrm{V}(1) \mathrm{O}_{6}$ octahedra and corner-sharing $\mathrm{V}(2) \mathrm{O}_{6}$ octahedra constitute $\left[\mathrm{V}_{4} \mathrm{O}_{11}\right]_{n}$ layers along the $b$ axis in form of zigzag chains and double chains (projection along the $a$-axis in Figure 1b), respectively, and the five-fold $\mathrm{V}(3) \mathrm{O}_{5}$ pyramids chains were acted as pillars to connect the layers by corner-shared oxygen. The formed tunnel-like $\beta$ phase vanadium oxide bronzes can facilely accommodate a large amount of $\mathrm{Li}^{+}$by the successive filling of different crystallographic sites in the tunneled host structure. Whereas the complicated crystal structure is ease to be transformed by the partial reduction or oxidation of the framework vanadium atoms, giving rise to undesired impurity phase. The XRD pattern of the rGO/LVO sample prepared by oven-drying was provided in Figure S1. Obviously, strong diffraction of $\mathrm{LiV}_{3} \mathrm{O}_{8}$ phase was detected in the $\mathrm{rGO} / \beta-\mathrm{Li}_{x} \mathrm{~V}_{2} \mathrm{O}_{5}$ sample, suggesting the unstable phase structure when dried in heating environment with reduced graphene oxide nanosheets. By comparison, the XRD patterns of the 
$\mathrm{rGO} / \mathrm{LaPO}_{4} / \mathrm{LVO}$ sample obtained by gentle frozen dryness were displayed in Figure 1c. The hydrothermal synthesized product labeled as LVO were assigned to the monoclinic $\beta-\mathrm{Li}_{x} \mathrm{~V}_{2} \mathrm{O}_{5}$ phase (JCPDS no. 73-1670). Noticeably, the modification samples of $\mathrm{LaPO}_{4} / \mathrm{LVO}$ and $\mathrm{rGO} / \mathrm{LaPO}_{4} / \mathrm{LVO}$ exhibit identical diffraction peaks with that of $\beta-\mathrm{Li}_{x} \mathrm{~V}_{2} \mathrm{O}_{5}$ phase.[29] Herein, the well-preserved $\beta$ - $\mathrm{Li}_{x} \mathrm{~V}_{2} \mathrm{O}_{5}$ phase after modification with electronic conductive rGO and ionic conductive $\mathrm{LaPO}_{4}$ further demonstrate that the frozen dryness strategy was effective to be applied in the surface modification for the vanadate compound with complex valence states. Besides, the diffraction peak of rGO and $\mathrm{LaPO}_{4}$ was absent in the XRD pattern, which was probably because of the relatively low diffraction intensity of rGO and trace amount of $\mathrm{LaPO}_{4}$.

The morphology of $\mathrm{rGO} / \mathrm{LaPO}_{4} / \mathrm{LVO}$ was characterized by SEM and TEM, and the results are shown in Figure 1d-f. It can be clearly seen that the LVO nanorods were about $300-500 \mathrm{~nm}$ in average diameter and $1-1.5 \mu \mathrm{m}$ in average length. LVO nanorods were well wrapped by reduced graphene oxide nanosheets without aggregation, which would bridge the electrical connection between the dispersed LVO nanorods effectively (Figure 1d). Noticeably, tiny nanoparticles were observed on the surface of $\mathrm{LVO}$ nanorods with $\mathrm{LaPO}_{4}$ coating even if the rods are wrapped by rGO nanosheets. From TEM image in Figure 1e, it can be seen that the LVO nanorods were covered by a crystalline layer with thickness of about $20 \mathrm{~nm}$. The high-resolution TEM image of LVO rods surface particle shown in Figure 1f presented a clear interplanar spacing 
lattice of $0.488 \mathrm{~nm}$ that was in agreement with the (110) crystal planes of the monoclinic $\mathrm{LaPO}_{4}$ phase, further proving that $\mathrm{LaPO}_{4}$ layer is successfully coated onto the LVO surface. Meanwhile, the energy dispersive X-ray spectroscopy (EDX) mapping of $\mathrm{rGO} / \mathrm{LaPO}_{4} / \mathrm{LVO}$ was displayed in Figure $\mathrm{S} 2$. As shown, the elements La and $\mathrm{P}$ were detected, which exhibit almost the same distribution with the elements $\mathrm{V}$ and $\mathrm{O}$. As shown, frozen dryness by liquid nitrogen freeze is a facile approach to realize the cooperation of reduced oxide graphene nanosheets with LVO rods.

Raman spectra of $\mathrm{LVO}$ and the $\mathrm{rGO} / \mathrm{LaPO}_{4} / \mathrm{LVO}$ sample were provided in Figure S3. Four prominent Raman bands around 143, 262, 514, 699 and 1005 $\mathrm{cm}^{-1}$ were observed. The frequency mode of 143 and $262 \mathrm{~cm}^{-1}$ in lower wavenumbers range was assigned to the bond bending vibrations and the frequency mode of 514, 699 and $1005 \mathrm{~cm}^{-1}$ in higher wavenumbers range were designated to the stretching vibrations of differing $\mathrm{V}-\mathrm{O}$ bonds, which was in good accordance with the Raman characteristic peaks of $\beta$-phase bronze $\mathrm{Li}_{x} \mathrm{~V}_{2} \mathrm{O}_{5}$ compounds.[15, 30] Besides, two typical $\mathrm{D}$ and $\mathrm{G}$ bands of graphene at 1340 and $1600 \mathrm{~cm}^{-1}$ were presented in the $\mathrm{rGO} / \mathrm{LaPO}_{4} / \mathrm{LVO}$ composite, which originated from the defects of disordered $\mathrm{sp}^{2}$ carbon atoms and graphite carbon, respectively.[31] The intensity ratio of $I_{\mathrm{D}} / I_{\mathrm{G}}$ was estimated to be 0.99 , suggesting the high quality of graphene in the $\mathrm{rGO} / \mathrm{LaPO}_{4} / \mathrm{LVO}$ composite.

The elemental valence states information in pristine LVO and modified samples were investigated by X-ray photoelectron spectroscopy. The XPS spectra of pristine $\mathrm{LVO}, \mathrm{LaPO}_{4} / \mathrm{LVO}$ and $\mathrm{rGO} / \mathrm{LaPO}_{4} / \mathrm{LVO}$ samples were provided in Figure 2a. As seen, the characteristic peak of lithium, vanadium and 
oxygen can be detected for all the prepared samples. Noticeably, the P2p peak centered at $102.1 \mathrm{eV}$ and the La3d peak located around $836 \mathrm{eV}$ can be observed on the XPS spectrum for $\mathrm{LaPO}_{4} / \mathrm{LVO}$ and $\mathrm{rGO} / \mathrm{LaPO}_{4} / \mathrm{LVO}$ sample, indicating the existence of $\mathrm{LaPO}_{4}$ component after surface modification. The high-resolution V2p spectra of the products before and after modification are displayed in Figure 2b. As shown, the V2p spectrum was composed of two characteristic peaks of $\mathrm{V} 2 \mathrm{p}^{3 / 2}$ and $\mathrm{V} 2 \mathrm{p}^{1 / 2}$ located at 517.4 and $524.9 \mathrm{eV}$, respectively. Notably, both of the V2 $\mathrm{p}^{3 / 2}$ and $\mathrm{V} 2 \mathrm{p}^{1 / 2}$ peak can be deconvoluted into two components with the strong one from the pentavalent state $\left(\mathrm{V}^{5+}\right)$ and the weak one from the tetravalent state $\left(\mathrm{V}^{4+}\right)$.[32] Based on the peak areas, the ratio of $\mathrm{V}^{4+}$ to $\mathrm{V}^{5+}$ in LVO sample was calculated to be 0.218 , which increase to 0.367 after surface modification with $\mathrm{rGO}$ and $\mathrm{LaPO}_{4}$. The slight increase of $\mathrm{V}^{4+}$ on the surface is reasonable because of the existence of reductive oxide graphene when annealed in the inert atmosphere, which might be beneficial for the electronic transfer with more pathways for electron hopping between $\mathrm{V}^{5+}$ and $\mathrm{V}^{4+}$.[33] Additionally, the characteristic XPS peak of La3d located at 839.0 $\mathrm{eV}$ along with a satellite peak around $835.8 \mathrm{eV}$ was detected in the rGO/LaPO $4 / \mathrm{LVO}$ composites (Figure 2c), further verifying the existence of $\mathrm{LaPO}_{4}$ coating layer.[34]

\subsection{Electrochemical properties of $\mathrm{rGO} / \mathrm{LaPO}_{4} / \mathrm{LVO}$ cathode}

In order to investigate the electrochemical behavior of $\beta-\mathrm{Li}_{x} \mathrm{~V}_{2} \mathrm{O}_{5}$ electrode after surface modification, the $\mathrm{CV}$ curves of $\mathrm{LVO}$ and $\mathrm{rGO} / \mathrm{LaPO}_{4} / \mathrm{LVO}$ electrodes were recorded at a scan rate of $0.05 \mathrm{mV} \mathrm{s}^{-1}$ in voltage range of 1.8-4.0 V (vs. $\mathrm{Li} / \mathrm{Li}^{+}$). As shown in Figure 3a, five distinct reduction peaks 
located at $3.60,3.42,2.87,2.56,1.90 \mathrm{~V}$ were observed for LVO electrode, corresponding to the $\mathrm{Li}^{+}$successive occupation processes of the specific lithium sites in tunneled framework.[14] For the pristine LVO electrode, large potential gap of around $0.36 \mathrm{~V}$ was observed for the redox peaks located at 2.92/2.56 V. In comparison, smaller potential difference of $0.23 \mathrm{~V}$ was displayed for the $\mathrm{rGO} / \mathrm{LaPO}_{4} / \mathrm{LVO}$ composite, implying that the electrochemical polarization was significantly alleviated and the charge transfer reactivity was improved with the conductive rGO layer. The complicated multistep $\mathrm{Li}^{+}$ insertion/extraction processes in vanadate electrode were derived from the energy differences for Li-ion holding in different Li sites.[35] Noticeably, the redox peak pairs centered at 2.87/2.91 V was absent in the $\mathrm{CV}$ curves of pristine LVO electrode, indicating the difficult extractions of lithium ions from the $\beta$ vanadium bronze structure, while that was clearly observed for $\mathrm{rGO} / \mathrm{LaPO}_{4} / \mathrm{LVO}$ electrode, further demonstrating that the multi-step intercalation and deintercalation of lithium ion in tunneled structure LVO was highly reversible with the presence of $\mathrm{rGO}$ and $\mathrm{LaPO}_{4}$ layer. From the $\mathrm{CV}$ curves of $\mathrm{rGO} / \mathrm{LaPO}_{4} / \mathrm{LVO}$ electrode with sharper redox peak and smaller redox potential difference, we can conclude that the $\mathrm{Li}^{+}$intercalation process was facilitated effectively by the assistance of $\mathrm{rGO}$ and $\mathrm{LaPO}_{4}$ layer.

$\mathrm{Next}$, the electrochemical performance of $\mathrm{rGO} / \mathrm{LaPO}_{4} / \mathrm{LVO}$ electrode were evaluated. The charge/discharge profiles of the $\mathrm{LVO}$ and $\mathrm{rGO} / \mathrm{LaPO}_{4} / \mathrm{LVO}$ electrodes cycled in the voltage window of $1.8-4.0 \mathrm{~V}$ at $60 \mathrm{~mA} \mathrm{~g}^{-1}$ was plotted 
in Figure $3 \mathrm{~b}$ and c. Five distinct discharge voltage plateaus around 3.6 V, 3.4 V, $2.8 \mathrm{~V}, 2.4 \mathrm{~V}$ and $1.9 \mathrm{~V}$ were observed, which was in good accordance with the $\mathrm{CV}$ curves, relating to the successive $\mathrm{Li}$ insertion steps into LVO tunneled crystal structure. Noticeably, the primary charge/discharge potential gap for $\mathrm{rGO} / \mathrm{LaPO}_{4} / \mathrm{LVO}$ electrode $(0.16 \mathrm{~V})$ was much smaller than the LVO electrode $(0.3 \mathrm{~V})$, further implying the alleviated electrochemical reaction polarization by surface modification. Meanwhile, the multiple charge/discharge voltages for rGO/LaPO$/ / L V O$ electrode were highly overlapped with clearly visible voltage plateaus during cycling (Figure 3c), which suffered from serious voltage decay for LVO electrode (Figure 3b), implying the gradual lithium trapping in the host lattice due to the sluggish $\mathrm{Li}^{+}$diffusion kinetics. The elevated electrochemical kinetics was exclusively due to highly conductive graphene matrix with large area, which could effectively facilitate the electronic transfer by providing more electric contact area between the active LVO nanorods.[36, 37]

To provide an intuitive observation of the intricate Li ordering steps in $\beta$ - $\mathrm{Li}_{x} \mathrm{~V}_{2} \mathrm{O}_{5}$, the crystal structure of $\beta-\mathrm{Li}_{x} \mathrm{~V}_{2} \mathrm{O}_{5}$ with possible $\mathrm{Li}^{+}$tunnel sites was illustrated in Figure 3d. For the $\beta-\mathrm{Li}_{x} \mathrm{~V}_{2} \mathrm{O}_{5}$, the pre-inserted $\mathrm{Li}^{+}$were randomly half-occupied in the tunnel sites that labeled M1 with the stoichiometric composition $x=0.33$ according to Wadsley. [38] Meanwhile, there also existed three alternative interstatial sites for $\mathrm{Li}^{+}$intercalation: eight-coordinated sites M2, tetrahedral sites M3, and octahedral sites M4 as shown in Figure 3d with 
different colors.[39] During the discharge process, the M2 and M3 sites would be half-occupied preferentially by inserted $\mathrm{Li}^{+}$which was governed by the repulsive coulometric interactions between neighboring sites. When the M1, M2, M3 tunnel sites are fully occupied, the filling of octahedral sites M4 would be possible, which corresponds to the last voltage plateau as shown in Figure 3b. Of particular note, the $\mathrm{Li}^{+}$filling step of M4 sites with the voltage plateau around $2 \mathrm{~V}$ was well-maintained for the $\mathrm{rGO} / \mathrm{LaPO}_{4} / \mathrm{LVO}$ electrode even after 100 cycles, further demonstrating the enhanced electrochemical reaction dynamics in $\beta-\mathrm{Li}_{x} \mathrm{~V}_{2} \mathrm{O}_{5}$ after surface modification.

Further, the cycling performance of $\mathrm{LVO}$ and $\mathrm{rGO} / \mathrm{LaPO}_{4} / \mathrm{LVO}$ electrodes at a current density of $60 \mathrm{~mA} \mathrm{~g}^{-1}$ was evaluated as shown in Figure 3e. The pristine LVO electrode delivered an initial discharge capacity of $282.5 \mathrm{mAh} \mathrm{g}^{-1}$, whereas suffered from serious capacity decay with relatively low capacity retention of $37.3 \%$ after 100 cycles. The severe capacity fades mainly originated from the poor intrinsic conductivity as well as potential vanadium dissolution for pristine LVO particles.[40] It was worth mentioning that the cyclic stability of LVO was enhanced dramatically when the coating of $\mathrm{LaPO}_{4}$ and rGO layer was introduced, which delivered high capacity retention up to $84.1 \%$ at a slight expense of specific capacity $\left(275.7 \mathrm{mAh} \mathrm{g}^{-1}\right)$. The cyclic stability of LVO electrode was boosted with the surface modified by protective and conductive layer, which was probably derived from the protective coating layer with the ability to prevent the electrode from electrolyte erosion as well as stabilize the crystal structure.[41]

On the other hand, surface modification with conductive rGO and ionic conductive $\mathrm{LaPO}_{4}$ is expected to facilitate the electrochemical reaction dynamics, so we also 
explore the rate capability of $\mathrm{LVO}$ and $\mathrm{rGO} / \mathrm{LaPO}_{4} / \mathrm{LVO}$ electrodes at different charge/discharge current densities as shown in Figure 3f. The LVO sample delivers specific discharge capacities of 321.9, 252.4, 193.7, 139.2, 93.4 and $48.2 \mathrm{mAh} \mathrm{g}^{-1}$ at current densities of $15,30,60,100,200$ and $400 \mathrm{~mA} \mathrm{~g}^{-1}$, respectively. Significant capacity decay was exhibited for pristine LVO electrode with the current density increasing. For the case of $\mathrm{rGO} / \mathrm{LaPO}_{4} / \mathrm{LVO}$ electrode, the specific discharge capacities were $315.8,263.2,226.3,203.3,186.6$ and $170.3 \mathrm{mAh} \mathrm{g}^{-1}$ at current densities of $15,30,60,100,200$ and $400 \mathrm{~mA} \mathrm{~g}^{-1}$, respectively. When the current density was set back to $15 \mathrm{~mA} \mathrm{~g}^{-1}$, as high as $291.3 \mathrm{mAh} \mathrm{g}^{-1}$ can be recovered for the $\mathrm{rGO} / \mathrm{LaPO}_{4} / \mathrm{LVO}$ electrode. It was worth to mention that the capacity varied slightly under every current density for the modification sample. In order to make an intuitive observation of the improved rate capability for modification electrode, the discharge curves of the $\mathrm{LVO}$ and $\mathrm{rGO} / \mathrm{LaPO}_{4} / \mathrm{LVO}$ electrode at different current densities were displayed in Figure S4a and b. Five discharge plateaus corresponding to the successive Li ordering processes in the $\beta$ tunnel framework were observed evidently on the discharge profiles for LVO electrode at $15 \mathrm{~mA} \mathrm{~g}{ }^{-1}$, which experienced noticeable voltage recession with the growing current density, implying the gradual capacity loss derived from lithium trapping in the host lattice due to the sluggish $\mathrm{Li}^{+}$ diffusion kinetics especially under high current densities.[42] For comparison, the discharge plateau was still distinct for $\mathrm{rGO} / \mathrm{LaPO}_{4} / \mathrm{LVO}$ electrode at current density up to $400 \mathrm{~mA} \mathrm{~g}^{-1}$, which is capable of delivering $\sim 75 \%$ of the reversible capacity discharged at $60 \mathrm{~mA} \mathrm{~g}^{-1}$, further suggesting the dramatically improved rate capability of LVO electrode with surface modification. The high rate capability and stable cyclability makes the $\mathrm{rGO} / \mathrm{LaPO}_{4} / \mathrm{LVO}$ composite competitive candidate for lithium ion batteries applications. 


\subsection{Mechanism insight of electrochemical performance improvement}

To further clarify the improved electrochemical performance of $\mathrm{rGO} / \mathrm{LaPO}_{4} / \mathrm{LVO}$ electrode, EIS was carried out to analyze the variation of electrode/electrolyte interface property during cycling. The Nyquist plots of $\mathrm{LVO}$ and $\mathrm{rGO} / \mathrm{LaPO}_{4} / \mathrm{LVO}$ electrode after initial cycling were provided in Figure $4 \mathrm{a}$. Both of the curves were composed of a semicircle in the high frequency followed by a straight line in the low frequency region, which are assigned to the charge transfer resistance $\left(R_{\mathrm{ct}}\right)$ on the electrode/electrolyte interface and the $\mathrm{Li}^{+}$diffusion within the bulk electrode materials, respectively.[43, 44] The resistance values of the $\mathrm{LVO}$ and $\mathrm{rGO} / \mathrm{LaPO}_{4} / \mathrm{LVO}$ electrodes were fitted by the equivalent circuit inset in Figure $4 \mathrm{a}$. The fitting data were shown in Table 1. Obviously, the $R_{\mathrm{ct}}$ value of $\mathrm{rGO} / \mathrm{LaPO}_{4} / \mathrm{LVO}(98.2 \Omega)$ is three times lower than that of the LVO electrode $(379.8 \Omega)$, implying the charge transfer resistance was reduced effectively upon rGO modification. Even after 100 cycles (shown in Figure $4 \mathrm{~b}$ ), the $\mathrm{rGO} / \mathrm{LaPO}_{4} / \mathrm{LVO}$ electrode still exhibits much lower $R_{\mathrm{ct}}$ than that of the LVO electrode, further indicating that the introduction of rGO and $\mathrm{LaPO}_{4}$ layer could stabilize the electrode/electrolyte interface, which contribute to the superior cyclic stability and rate capability during charge/discharge processes. The $\mathrm{Li}$ ion diffusion coefficient can be calculated by the following equation:[45]

$$
D_{L i+}=0.5 R^{2} T^{2} / S^{2} n^{4} F^{4} C^{2} \sigma^{2}
$$

where $R$ is the gas constant $\left(8.314 \mathrm{~J} \mathrm{~mol}^{-1} \mathrm{~K}^{-1}\right), T$ is the temperature $(298 \mathrm{~K}), S$ is the electrode area $\left(1.54 \mathrm{~cm}^{2}\right), n$ is the number of electron transfer, $F$ is the Faraday constant $\left(96500 \mathrm{C} \mathrm{mol}^{-1}\right), C$ is the molar concentration of the $\mathrm{Li}^{+}$in the cathode calculated on the basis of the crystallographic cell parameter of LVO, and $\sigma$ is the Warburg impedance coefficient obtained from the slope of fitting lines as shown in Figure 4c. The $\mathrm{Li}^{+}$diffusion coefficient of $\mathrm{rGO} / \mathrm{LaPO}_{4} / \mathrm{LVO}$ is calculated to be 
$4.67 \times 10^{-14} \mathrm{~cm}^{2} \mathrm{~s}^{-1}$, which is approximately one order higher than that of pristine LVO $\left(2.08 \times 10^{-15} \mathrm{~cm}^{2} \mathrm{~s}^{-1}\right)$. The evidently increased $\mathrm{Li}^{+}$diffusion coefficient suggests that the surface layer of $\mathrm{LaPO}_{4}$ is favorable to accelerate the diffusion of lithium ions and enhance the reversibility of lithium ion insertion/extraction in tunnel structure.[46]

To highlight the advantages of surface engineering on LVO electrode, the differential capacity $(\mathrm{d} Q / \mathrm{d} V)$ plots of $\mathrm{LVO}$ and $\mathrm{rGO} / \mathrm{LaPO}_{4} / \mathrm{LVO}$ electrodes after 100 cycles were presented in Figure 4d. Obviously, strong and sharp redox peaks were still observed evidently on the $\mathrm{dQ} / \mathrm{dV}$ curves for the $\mathrm{rGO} / \mathrm{LaPO}_{4} / \mathrm{LVO}$ electrode even after 100 cycles, which almost disappeared for the pristine LVO accompanied by serious capacity decay, further revealing that surface co-modification was effective to improve the reversibility of repeated lithium ion insertion/extraction in LVO cathode.

Furthermore, XRD and SEM characterization was utilized to investigate the change of crystal structure and morphology during cycling. Figure 5a shows the XRD patterns of the $\mathrm{LVO}$ and $\mathrm{rGO} / \mathrm{LaPO}_{4} / \mathrm{LVO}$ electrodes before and after 100 cycles. For the cycled LVO electrode, the main diffraction peak intensity of (002) plane was rather weak, which was still maintained sharp and strong for the modified LVO electrode, suggesting the crystal structure was well-preserved upon cycling, which was primarily benefited by the effective protection of crystal structure from electrolyte corrosion by surface modification layer. Figure 5c and e shows the SEM images of the $\mathrm{LVO}$ and $\mathrm{rGO} / \mathrm{LaPO}_{4} / \mathrm{LVO}$ electrodes after 100 cycles. Inevitably, cracks occurred on the LVO nanorods surface induced by the structural stress during lithiation processes, while intact nanorod surface was preserved for $\mathrm{rGO} / \mathrm{LaPO}_{4} / \mathrm{LVO}$ electrodes even after long-term cycling as shown in Figure 5e, further verifying the improved structural stability and reversibility for the modified LVO electrode.

Based on above discussion, the interfacial schematic illustration of LVO with rGO 
and $\mathrm{LaPO}_{4}$ surface layer is schematically demonstrated in Figure 6. The LVO nanorods was distributed uniformly on the conductive rGO matrix. During discharge process, the electronic transmission between the active LVO nanorods was promoted efficiently through rGO layer which act as "bridge" to connect the adjacent LVO nanorods together. Meanwhile, the interfacial $\mathrm{Li}^{+}$diffusion between the bulk LVO electrode and electrolyte was also facilitated by the $\mathrm{LaPO}_{4}$ layer, which was favorable for the excellent rate capability. Additionally, the protective layer of $\mathrm{LaPO}_{4}$ and $\mathrm{rGO}$ would stabilize the electrode/electrolyte interface and protect the LVO particles from electrolyte corrosion, contributing to the improved structural stability and cyclic stability during repeated $\mathrm{Li}$ insertion/extraction processes.

\section{Conclusions}

To summarize, we successfully prepared $\mathrm{rGO} / \mathrm{LaPO}_{4} / \mathrm{Li}_{x} \mathrm{~V}_{2} \mathrm{O}_{5}$ composite electrode via chemical precipitation and frozen dryness. The $\mathrm{rGO} / \mathrm{LaPO}_{4} / \mathrm{LVO}$ composite demonstrated significantly improved cyclic stability and rate capability. At a current density of $60 \mathrm{~mA} \mathrm{~g}{ }^{-1}$, the $\mathrm{rGO} / \mathrm{LaPO}_{4} / \mathrm{LVO}$ electrode delivered high reversible capacity of $275.7 \mathrm{mAh} \mathrm{g}^{-1}$ with high capacity retention of $84.1 \%$ after 100 cycles. The enhanced electrochemical performance of the LVO electrode is ascribed to the promoted electronic transfer and $\mathrm{Li}^{+}$diffusion coefficient between active nanorods with the functionality of conductive $\mathrm{rGO}$ and $\mathrm{LaPO}_{4}$ layer. The excellent electrochemical properties of $\mathrm{rGO} / \mathrm{LaPO}_{4} / \mathrm{LVO}$ composites, together with their high specific capacity and rate capability, make tunneled lithium vanadate promising candidate for next-generation rechargeable lithium ion batteries.

\section{Acknowledgements}

This work was partially supported by Economic, Trade and Information Commission of Shenzhen Municipality through the Graphene Manufacture Innovation 
Center (grant no. 201901161514), and Shenzhen Science and Technology Innovation Committee (JCYJ20151013162733704). P.P.W. and Y.D. acknowledge the support from China Postdoctoral Science Foundation with grant numbers of 2018M641823 and 2017M621287, respectively.

\section{Appendix A. Supporting information}

Supplementary data associated with this article can be found in the online version. 


\section{References:}

[1] J.B. Goodenough, K.S. Park, The Li-ion rechargeable battery: a perspective, J Am Chem Soc 135(4) (2013) 1167-76.

[2] B. Diouf, R. Pode, Potential of lithium-ion batteries in renewable energy, Renewable Energy 76 (2015) 375-380.

[3] B. Scrosati, J. Garche, Lithium batteries: Status, prospects and future, J. Power Sources 195(9) (2010) 2419-2430.

[4] F. Maroni, A. Birrozzi, G. Carbonari, F. Croce, R. Tossici, S. Passerini, F. Nobili, Graphene $/ \mathrm{V}_{2} \mathrm{O}_{5}$ Cryogel Composite As a High-Energy Cathode Material For Lithium-Ion Batteries, ChemElectroChem 4(3) (2017) 613-619.

[5] S. Choi, G. Wang, Advanced Lithium-Ion Batteries for Practical Applications: Technology, Development, and Future Perspectives, Adv. Mater. Technologies 3(9) (2018) 1700376.

[6] P.-P. Wang, C.-Y. Xu, L. Wang, B.-Y. Zhang, L. Zhen, Electrochemical behavior and structural stability of $\mathrm{LiV}_{3} \mathrm{O}_{8}$ microrods as cathode for lithium-ion batteries, Ceram. Int. 42(16) (2016) 18747-18755.

[7] Y. Zhao, C. Han, J. Yang, J. Su, X. Xu, S. Li, L. Xu, R. Fang, H. Jiang, X. Zou, B. Song, L. Mai, Q. Zhang, Stable alkali metal ion intercalation compounds as optimized metal oxide nanowire cathodes for lithium batteries, Nano Lett. 15(3) (2015) 2180-5. [8] P.M. Marley, G.A. Horrocks, K.E. Pelcher, S. Banerjee, Transformers: the changing phases of low-dimensional vanadium oxide bronzes, Chem. Commun. 51(25) (2015) 5181-98.

[9] N.A. Chernova, M. Roppolo, A.C. Dillon, M.S. Whittingham, Layered vanadium and molybdenum oxides: batteries and electrochromics, J. Mater. Chem. 19(17) (2009) 2526.

[10] C. Leger, S. Bach, P. Soudan, J.P. Pereira-Ramos, Structural and Electrochemical Properties of $\omega-\mathrm{Li}_{x} \mathrm{~V}_{2} \mathrm{O}_{5} \quad(0.4 \leqslant x \leqslant 3)$ as Rechargeable Cathodic Material for Lithium Batteries, J. Electrochem. Soc. 152 (2005) A236-A241.

[11] Y. Xu, X. Han, L. Zheng, W. Yan, Y. Xie, Pillar effect on cyclability 
enhancement for aqueous lithium ion batteries: a new material of $\beta$-vanadium bronze $\mathrm{M}_{0.33} \mathrm{~V}_{2} \mathrm{O}_{5}(\mathrm{M}=\mathrm{Ag}, \mathrm{Na})$ nanowires, J. Mater. Chem. 21(38) (2011) 14466.

[12] W.D. Li, C.Y. Xu, Y. Du, H.T. Fang, Y. Feng, L. Zhen, Electrochemical Lithium Insertion Behavior of $\beta-\mathrm{Li}_{x} \mathrm{~V}_{2} \mathrm{O}_{5}(0<x \leqslant 3)$ as the Cathode Material for Secondary Lithium Batteries, J. Electrochem. Soc. 161(1) (2014) A75-A83.

[13] N.M. Asl, J. Kim, W.C. Lee, Z. Liu, P. Lu, Y. Kim, A new chemical route for the synthesis of $\beta^{\prime}-\mathrm{Li}_{x} \mathrm{~V}_{2} \mathrm{O}_{5}$ for use as a high performance cathode, Electrochim. Acta 105 (2013) 403-411.

[14] J. Jiang, Z.X. Wang, L.Q. Chen, Structural and electrochemical studies on $\beta-\mathrm{Li}_{x} \mathrm{~V}_{2} \mathrm{O}_{5}$ as cathode material for rechargeable lithium batteries, J. Phys. Chem. C 111 (2007) 10707-10711.

[15] W.D. Li, C.Y. Xu, X.L. Pan, Y.D. Huang, L. Zhen, High capacity and enhanced structural reversibility of $\beta-\mathrm{Li}_{x} \mathrm{~V}_{2} \mathrm{O}_{5}$ nanorods as the lithium battery cathode, J. Mater. Chem. A 1(17) (2013) 5361-5370.

[16] R.W. Mo, F.W. Zhang, Y. Du, Z.Y. Lei, D. Rooney, K.N. Sun, Sandwich nanoarchitecture of $\mathrm{LiV}_{3} \mathrm{O}_{8} /$ graphene multilayer nanomembranes via layer-by-layer self-assembly for long-cycle-life lithium-ion battery cathodes, J. Mater. Chem. A 3(26) (2015) 13717-13723.

[17] Y. Wang, G.Z. Cao, Synthesis and Enhanced Intercalation Properties of Nanostructured Vanadium Oxides, Chem. Mater. (18) (2006) 2787-2804.

[18] H.Q. Song, M.S. Luo, A.M. Wang, High Rate and Stable Li-Ion Insertion in Oxygen-Deficient $\mathrm{LiV}_{3} \mathrm{O}_{8}$ Nanosheets as a Cathode Material for Lithium-Ion Battery, ACS Appl. Mater. Interfaces 9(3) (2017) 2875-2882.

[19] K.X. Wang, X.H. Li, J.S. Chen, Surface and interface engineering of electrode materials for lithium-ion batteries, Adv. Mater. 27(3) (2015) 527-45.

[20] Y.K. Lu, J. Wu, J. Liu, M. Lei, S.S. Tang, P.J. Lu, L.Y. Yang, H.R. Yang, Q. Yang, Facile Synthesis of $\mathrm{Na}_{0.33} \mathrm{~V}_{2} \mathrm{O}_{5}$ Nanosheet-Graphene Hybrids as Ultrahigh Performance Cathode Materials for Lithium Ion Batteries, ACS Appl. Mater. Interfaces 7(31) (2015) 17433-40.

[21] R.W. Mo, Y. Du, N.Q. Zhang, D. Rooney, K.N. Sun, In situ synthesis of $\mathrm{LiV}_{3} \mathrm{O}_{8}$ 
nanorods on graphene as high rate-performance cathode materials for rechargeable lithium batteries, Chem. Commun. 49(80) (2013) 9143-5.

[22] H.Y. Kang, Y.C. Liu, M.H. Shang, T.Y. Lu, Y.J. Wang, L.F. Jiao, $\mathrm{NaV}_{3} \mathrm{O}_{8}$ nanosheet@polypyrrole core-shell composites with good electrochemical performance as cathodes for Na-ion batteries, Nanoscale 7(20) (2015) 9261-9267.

[23] H.P. Guo, L. Liu, Q.L. Wei, H.B. Shu, X.K. Yang, Z.H. Yang, M. Zhou, J.L. Tan, Z.C. Yan, X.Y. Wang, Electrochemical characterization of polyaniline- $\mathrm{LiV}_{3} \mathrm{O}_{8}$ nanocomposite cathode material for lithium ion batteries, Electrochim. Acta 94 (2013) $113-123$.

[24] L.F. Jiao, L. Liu, J. Sun, L. Yang, Y.H. Zhang, H.T. Yuan, Y.M. Wang, X.D. Zhou, Effect of $\mathrm{AlPO}_{4}$ Nanowire Coating on the Electrochemical Properties of $\mathrm{LiV}_{3} \mathrm{O}_{8}$ Cathode Material, J. Phys. Chem. C 112 (2008) 18249-18254.

[25] R.W. Mo, Y. Du, N.Q. Zhang, D. Rooney, K.N. Sun, Surface modification of $\mathrm{LiV}_{3} \mathrm{O}_{8}$ nanosheets via layer-by-layer self-assembly for high-performance rechargeable lithium batteries, J. Power Sources 257 (2014) 319-324.

[26] S. Huang, J.P. Tu, X.M. Jian, Y. Lu, S.J. Shi, X.Y. Zhao, T.Q. Wang, X.L. Wang, C.D. $\mathrm{Gu}$, Enhanced electrochemical properties of $\mathrm{Al}_{2} \mathrm{O}_{3}$-coated $\mathrm{LiV}_{3} \mathrm{O}_{8}$ cathode materials for high-power lithium-ion batteries, Journal of Power Sources 245 (2014) 698-705.

[27] Y.Y. Shao, J. Wang, M. Engelhard, C.M. Wang, Y.H. Lin, Facile and controllable electrochemical reduction of graphene oxide and its applications, $\mathrm{J}$. Mater. Chem. 20(4) (2010) 743-748.

[28] W. Zhang, P.J. Zuo, C. Chen, Y.L. Ma, X.Q. Cheng, C.Y. Du, Y.Z. Gao, G.P. Yin, Facile synthesis of binder-free reduced graphene oxide/silicon anode for high-performance lithium ion batteries, J. Power Sources 312 (2016) 216-222.

[29] J. Bao, M. Zhou, Y.Q. Zeng, L.F. Bai, X.D. Zhang, K. Xu, Y. Xie, $\mathrm{Li}_{0.3} \mathrm{~V}_{2} \mathrm{O}_{5}$ with high lithium diffusion rate: a promising anode material for aqueous lithium-ion batteries with superior rate performance, J. Mater. Chem. A 1(17) (2013) 5423-5429. [30] R. Baddour-Hadjean, S. Bach, N. Emery, J.P. Pereira-Ramos, The peculiar structural behaviour of $\beta-\mathrm{Na}_{0.33} \mathrm{~V}_{2} \mathrm{O}_{5}$ upon electrochemical lithium insertion, J. Mater. 
Chem. 21(30) (2011) 11296.

[31] J.T. Xu, M. Wang, N.P. Wickramaratne, M. Jaroniec, S.X. Dou, L.M. Dai, High-performance sodium ion batteries based on a 3D anode from nitrogen-doped graphene foams, Adv. Mater. 27(12) (2015) 2042-2048.

[32] P.P. Wang, C.Y. Xu, F.X. Ma, L. Yang, L. Zhen, In situ soft-chemistry synthesis of $\beta-\mathrm{Na} 0.33 \mathrm{~V}_{2} \mathrm{O}_{5}$ nanorods as high-performance cathode for lithium-ion batteries, RSC Adv. 6(107) (2016) 105833-105839.

[33] H. Song, M. Luo, A. Wang, High Rate and Stable Li-Ion Insertion in Oxygen-Deficient $\mathrm{LiV}_{3} \mathrm{O}_{8}$ Nanosheets as a Cathode Material for Lithium-Ion Battery, ACS Appl Mater Interfaces 9(3) (2017) 2875-2882.

[34] M.L. Li, L.X. Zhang, X.Q. Fan, M.Y. Wu, M. Wang, R.L. Cheng, L.L. Zhang, H.L. Yao, S.J. Lin, Core-shell $\mathrm{LaPO}_{4} / \mathrm{g}-\mathrm{C}_{3} \mathrm{~N}_{4}$ nanowires for highly active and selective CO 2 reduction, Appl. Catal. B-Environ. 201 (2017) 629-635.

[35] J. Kawakita, M. Majima, T. Miura, T. Kishi, Preparation and lithium insertion behaviour of oxygen-deficient $\mathrm{Li}_{1+x} \mathrm{~V}_{3} \mathrm{O}_{8}-\delta$. J. Power Sources 66 (1997) 135-139.

[36] J.L. Cheng, B. Wang, H.L. Xin, G.C. Yang, H.Q. Cai, F.D. Nie, H. Huang, Self-assembled $\mathrm{V}_{2} \mathrm{O}_{5}$ nanosheets_reduced graphene oxide hierarchical nanocomposite as a high-performance cathode material for lithium ion batteries, J. Mater. Chem. A 1 (2013) 10814-10820.

[37] Y.L. Zhao, J.G. Feng, X. Liu, F.C. Wang, L.F. Wang, C.W. Shi, L. Huang, X. Feng, X.Y. Chen, L. Xu, M.Y. Yan, Q.J. Zhang, X.D. Bai, H.G. Wu, L.Q. Mai, Self-adaptive strain-relaxation optimization for high-energy lithium storage material through crumpling of graphene, Nat. Commun. 5 (2014) 4565.

[38] A.D. Wadsley, The crystal structure of $\mathrm{Na}_{2-x} \mathrm{~V}_{6} \mathrm{O}_{15}$, Acta Cryst. 8 (1955) 695-701.

[39] J.D. J. Galy, A. Casalot, J. B. Goodenough, Structure of the $\mathrm{M}_{x} \mathrm{~V}_{2} \mathrm{O}_{5-\beta}$ and $\mathrm{M}_{x} \mathrm{~V}_{2-y} \mathrm{TyO}_{5-\beta}$ Phases, J. Solid State Chem. 1 (1970) 339-348.

[40] X. Sun, C.G. Zhou, M. Xie, T. Hu, H.T. Sun, G.Q. Xin, G.K. Wang, S.M. Georgec, J. Lian, Amorphous vanadium oxide coating on graphene by atomic layer deposition for stable high energy lithium ion anodes, Chem. Commun. 50(73) (2014) 
10703-10706.

[41] R. Mo, F. Zhang, Y. Du, Z. Lei, D. Rooney, K. Sun, Sandwich nanoarchitecture of $\mathrm{LiV}_{3} \mathrm{O}_{8} /$ graphene multilayer nanomembranes via layer-by-layer self-assembly for long-cycle-life lithium-ion battery cathodes, J. Mater. Chem. A 3(26) (2015) $13717-13723$.

[42] K. West, B. Zachau-Christiansen, T. Jacobsen, S. Skaarup, Lithium insertion into vanadium pentoxide bronzes, Solid State Ionics (76) (1995) 15-21.

[43] A. Sakunthala, M.V. Reddy, S. Selvasekarapandian, B.V.R. Chowdari, P.C. Selvind, Energy storage studies of bare and doped vanadium pentoxide, $\left(\mathrm{V}_{1.95} \mathrm{M}_{0.05}\right) \mathrm{O}_{5}, \mathrm{M}=\mathrm{Nb}$, Ta, for lithium ion batteries, Energ. Environ. Sci. 4 (2011) $1712-1725$.

[44] B. Yan, M.S. Li, X.F. Li, Z.M. Bai, L. Dong, D.J. Li, Electrochemical Impedance Spectroscopy Illuminating Performance Evolution of Porous Core-Shell Structured Nickel_Nickel Oxide Anode Materials, Electrochim. Acta 164 (2015) 55-61.

[45] F. Gao, Z.Y. Tang, Kinetic behavior of $\mathrm{LiFePO}_{4} / \mathrm{C}$ cathode material for lithium-ion batteries, Electrochim. Acta 53(15) (2008) 5071-5075.

[46] Z. Ma, Y. Peng, G. Wang, Y. Fan, J. Song, T. Liu, X. Qin, G. Shao, Enhancement of electrochemical performance for LiFePO4 cathodes via hybrid coating with electron conductor carbon and lithium ion conductor LaPO4, Electrochim. Acta 156 (2015) 77-85. 


\section{Figures and Captions:}

Figure 1 Crystal structure and morphology characterization. (a, b) Crystal structure of $\beta$ - $\mathrm{Li}_{x} \mathrm{~V}_{2} \mathrm{O}_{5}$ with different projections along $b$ and $a$-axis, respectively. $\mathrm{V} 1$ represent the edge-sharing $\mathrm{VO}_{6}$ octahedra, $\mathrm{V} 2$ represents the corner-sharing $\mathrm{VO}_{6}$ octahedra, and $\mathrm{V} 3$ represents the $\mathrm{VO}_{5}$ pyramids. (c) XRD patterns of $\mathrm{LVO}, \mathrm{LaPO}_{4} / \mathrm{LVO}$ and $\mathrm{rGO} / \mathrm{LaPO}_{4} / \mathrm{LVO}$. The standard patterns of $\mathrm{Li}_{0.33} \mathrm{~V}_{2} \mathrm{O}_{5}$ is shown in the lower panel. (d)

SEM, (e) TEM and (f) HRTEM images of $\mathrm{LaPO}_{4}$-coated $\mathrm{LVO}$ nanorods wrapped by rGO nanosheets. Inset in (e) is enlarged view of the interface.

Figure 2 XPS spectra of $\mathrm{LVO} \mathrm{LaPO}_{4} / \mathrm{LVO}$ and $\mathrm{rGO} / \mathrm{LaPO}_{4} / \mathrm{LVO}$. (a) Survey spectra; (b) V2p; (c) core-level XPS spectra of La3d.

Figure 3 Electrochemical performance of $\mathrm{LVO}$ and $\mathrm{rGO} / \mathrm{LaPO}_{4} / \mathrm{LVO}$ electrodes. (a) $\mathrm{CV}$ curves at scan rate of $0.05 \mathrm{mV} \mathrm{s}^{-1}$. (b) Charge/discharge curves of LVO electrode. (c) Charge/discharge curves of $\mathrm{rGO} / \mathrm{LaPO}_{4} / \mathrm{LVO}$ electrode. (d) Crystal structure of $\beta$ - $\mathrm{Li}_{x} \mathrm{~V}_{2} \mathrm{O}_{5}$ with four possible tunnel sites for the inserted $\mathrm{Li}^{+}$in the $\beta$ structure marked with different colors. (e) Cycling performance at current density of $60 \mathrm{~mA} \mathrm{~g}^{-1}$. (f) Rate capability at current densities of 15 to $400 \mathrm{~mA} \mathrm{~g}^{-1}$.

Figure 4 Electrochemical impedance spectrum analysis before and after 100 cycles. (a) Nyquist plots of $\mathrm{LVO}$ and $\mathrm{rGO} / \mathrm{LaPO}_{4} / \mathrm{LVO}$ electrodes after initial cycles. Inset is the equivalent circuit for EIS fitting. (b) Nyquist plots of LVO and $\mathrm{rGO} / \mathrm{LaPO}_{4} / \mathrm{LVO}$ electrodes after 100 cycles. (c) The relationship between $Z^{\prime}$ and $\omega^{-1 / 2}$ in the low-frequency range. (d) Differential capacity $(\mathrm{d} Q / \mathrm{d} V)$ curves of LVO and $\mathrm{rGO} / \mathrm{LaPO}_{4} / \mathrm{LVO}$ electrodes after 100 cycles.

Figure 5 Structural and morphology characterization of LVO electrode upon cycling. (a) XRD pattern with magnified patterns of the $\mathrm{LVO}$ and $\mathrm{rGO} / \mathrm{LaPO}_{4} / \mathrm{LVO}$ electrodes 
after 100 cycles. (b) and (c) SEM images of the LVO electrodes before and after 100 cycles. (d) and (e) SEM images of the $\mathrm{rGO} / \mathrm{LaPO}_{4} / \mathrm{LVO}$ electrode before and after 100 cycles.

Figure 6 The interfacial schematic diagram of LVO electrode with $\mathrm{rGO}$ and $\mathrm{LaPO}_{4}$ layer, which provide effective electronic transport path and protect electrode surface from electrolyte corrosion. 

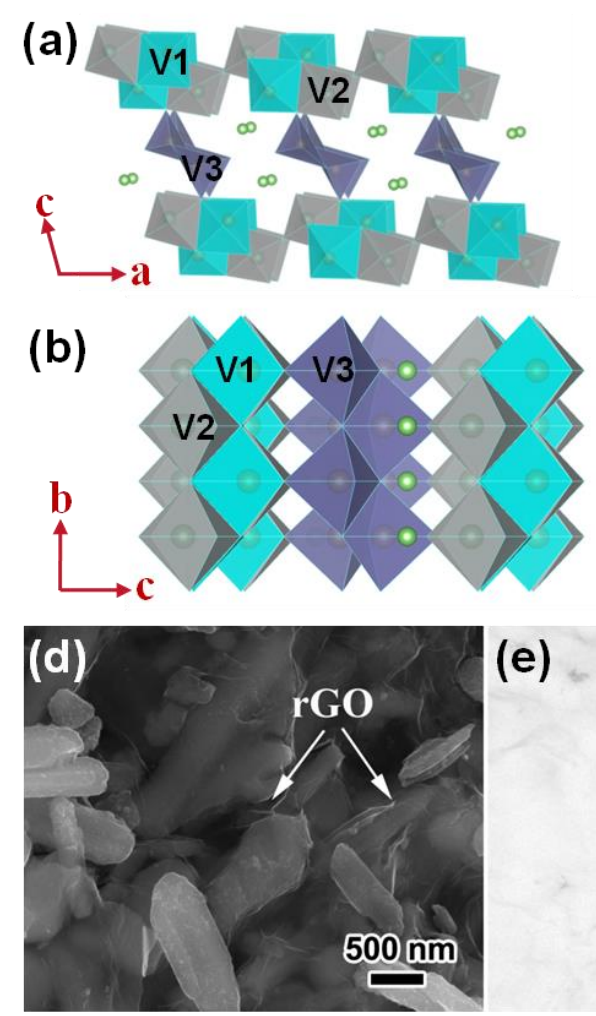

(e)
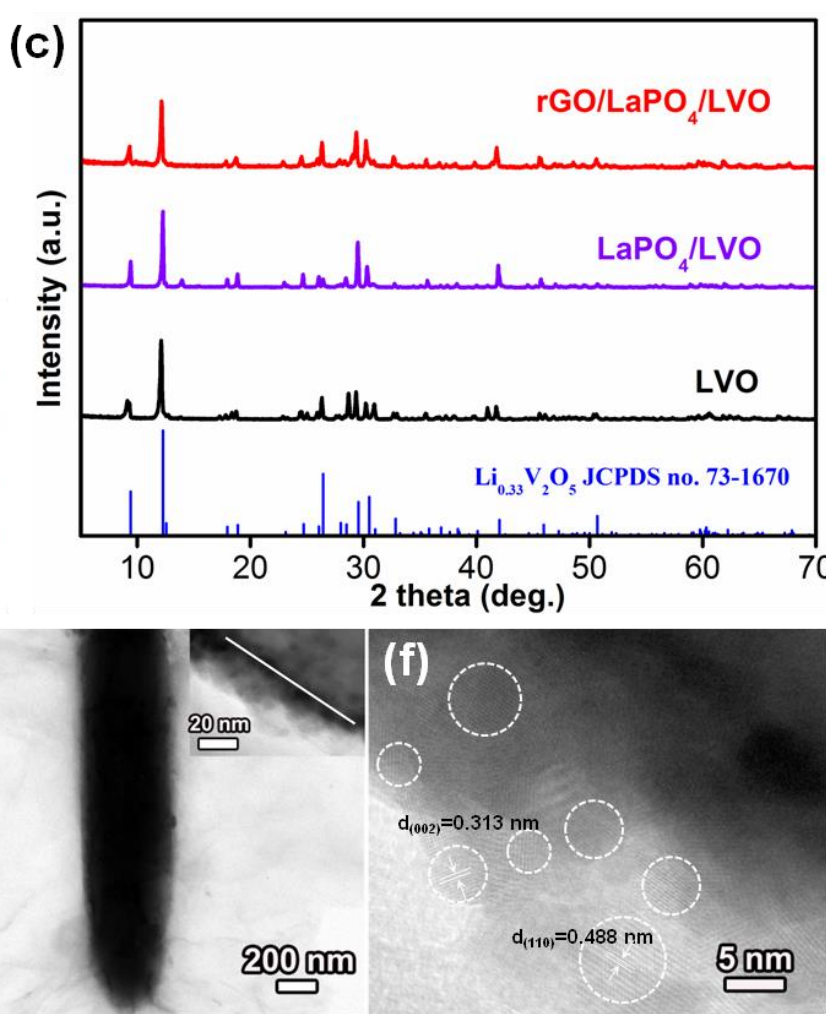

Figure 1 Crystal structure and morphology characterization. (a, b) Crystal structure of $\beta-\mathrm{Li}_{x} \mathrm{~V}_{2} \mathrm{O}_{5}$ with different projections along $b$ and $a$-axis, respectively. V1 represent the edge-sharing $\mathrm{VO}_{6}$ octahedra, $\mathrm{V} 2$ represents the corner-sharing $\mathrm{VO}_{6}$ octahedra, and $\mathrm{V} 3$ represents the $\mathrm{VO}_{5}$ pyramids. (c) XRD patterns of $\mathrm{LVO}, \mathrm{LaPO}_{4} / \mathrm{LVO}$ and $\mathrm{rGO} / \mathrm{LaPO}_{4} / \mathrm{LVO}$. The standard patterns of $\mathrm{Li}_{0.33} \mathrm{~V}_{2} \mathrm{O}_{5}$ is shown in the lower panel. (d) SEM, (e) TEM and (f) HRTEM images of $\mathrm{LaPO}_{4}$-coated LVO nanorods wrapped by rGO nanosheets. Inset in (e) is enlarged view of the interface.
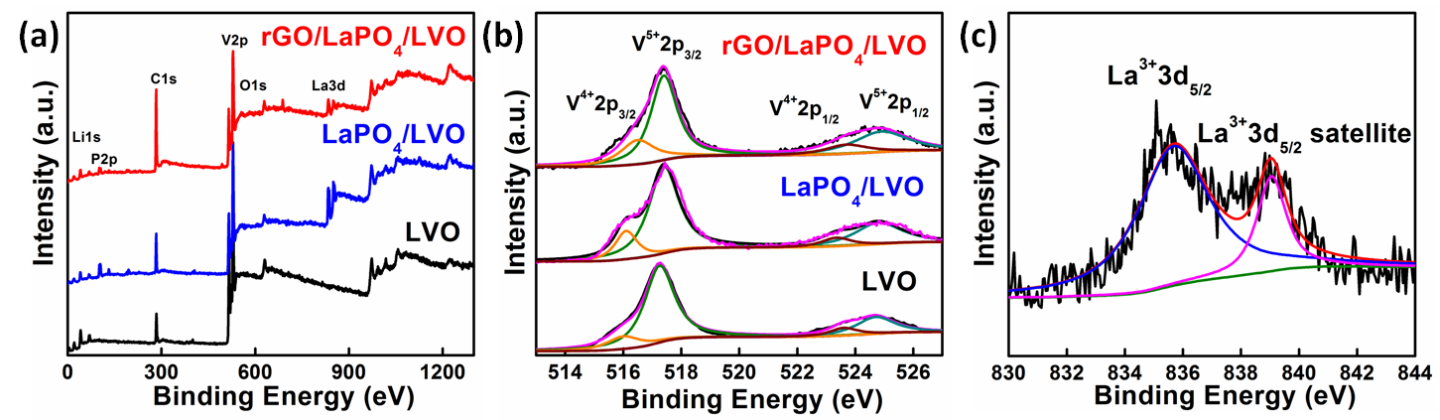

Figure 2 XPS spectra of $\mathrm{LVO}, \mathrm{LaPO}_{4} / \mathrm{LVO}$ and $\mathrm{rGO} / \mathrm{LaPO}_{4} / \mathrm{LVO}$. (a) Survey spectra; (b) V2p; (c) core-level XPS spectra of La3d. 

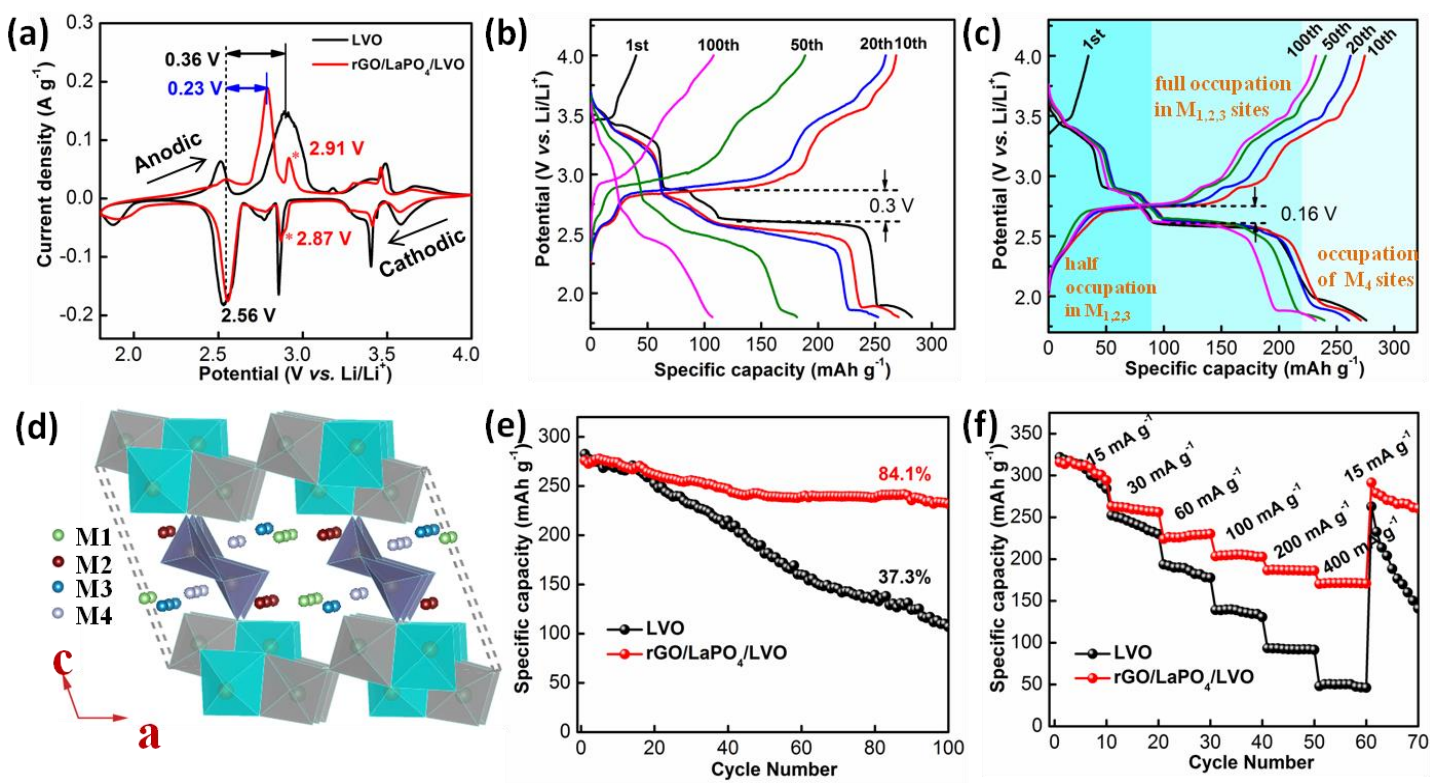

Figure 3 Electrochemical performance of $\mathrm{LVO}$ and $\mathrm{rGO} / \mathrm{LaPO}_{4} / \mathrm{LVO}$ electrodes. (a) $\mathrm{CV}$ curves at scan rate of $0.05 \mathrm{mV} \mathrm{s}^{-1}$. (b) Charge/discharge curves of LVO electrode. (c) Charge/discharge curves of $\mathrm{rGO} / \mathrm{LaPO} \mathrm{A}_{4} / \mathrm{LVO}$ electrode. (d) Crystal structure of $\beta-\mathrm{Li}_{x} \mathrm{~V}_{2} \mathrm{O}_{5}$ with four possible tunnel sites for the inserted $\mathrm{Li}^{+}$in the $\beta$ structure marked with different colors. (e) Cycling performance at current density of $60 \mathrm{~mA} \mathrm{~g}^{-1}$. (f) Rate capability at current densities of 15 to $400 \mathrm{~mA} \mathrm{~g}^{-1}$. 

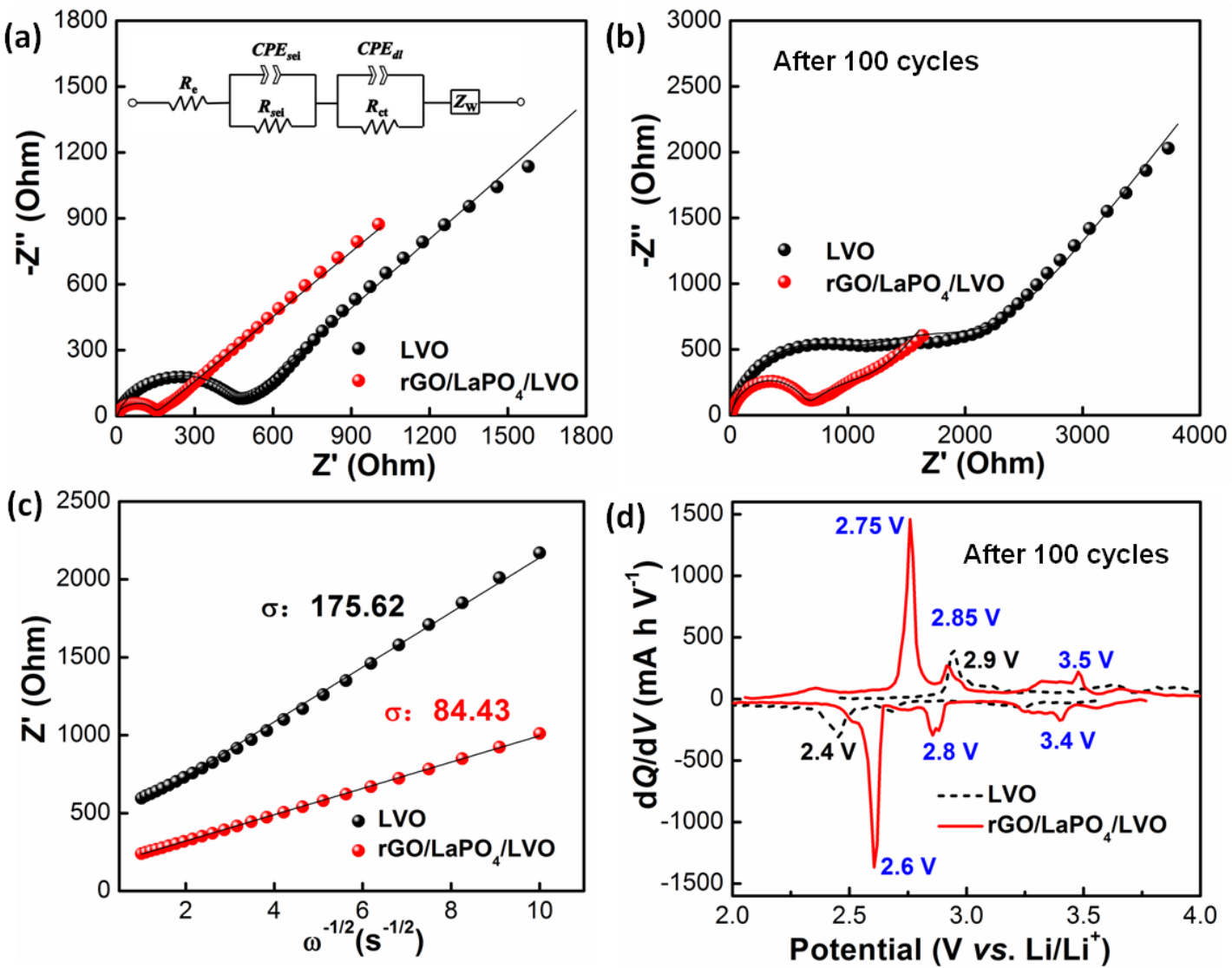

Figure 4 Electrochemical impedance spectrum analysis before and after 100 cycles. (a) Nyquist plots of $\mathrm{LVO}$ and $\mathrm{rGO} / \mathrm{LaPO}_{4} / \mathrm{LVO}$ electrodes after initial cycles. Inset is the equivalent circuit for EIS fitting. (b) Nyquist plots of $\mathrm{LVO}$ and $\mathrm{rGO} / \mathrm{LaPO}_{4} / \mathrm{LVO}$ electrodes after 100 cycles. (c) The relationship between $Z^{\prime}$ and $\omega^{-1 / 2}$ in the low-frequency range. (d) Differential capacity (d $Q / \mathrm{d} V$ ) curves of $\mathrm{LVO}$ and $\mathrm{rGO} / \mathrm{LaPO}_{4} / \mathrm{LVO}$ electrodes after 100 cycles. 

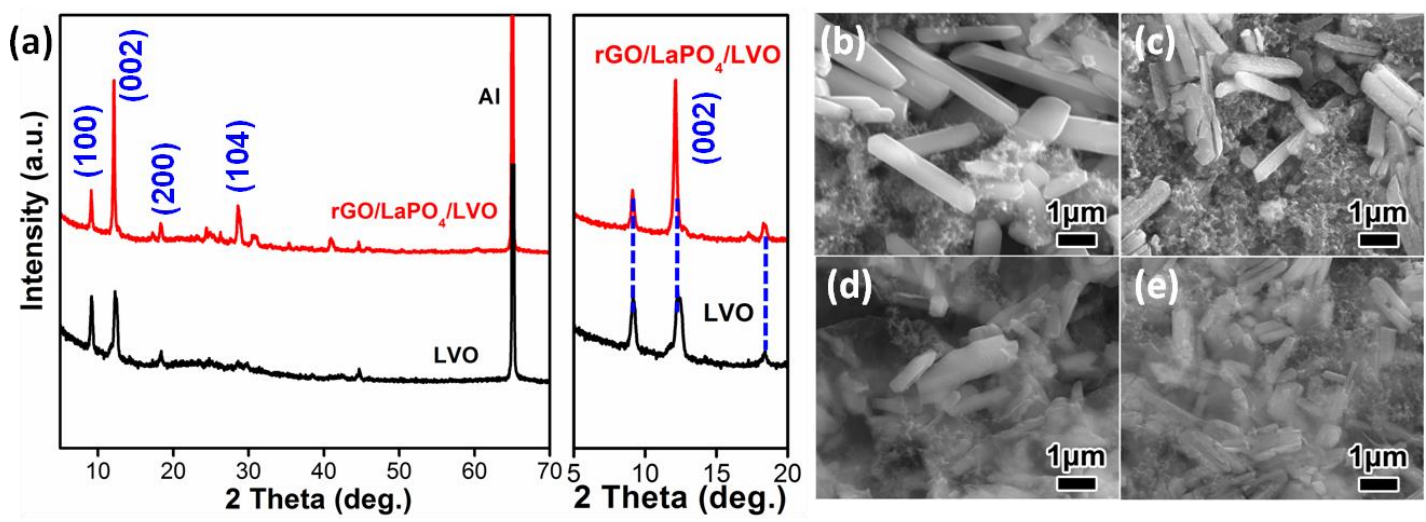

Figure 5 Structural and morphology characterization of LVO electrode upon cycling. (a) XRD pattern with magnified patterns of the $\mathrm{LVO}$ and $\mathrm{rGO} / \mathrm{LaPO}_{4} / \mathrm{LVO}$ electrodes after 100 cycles. (b) and (c) SEM images of the LVO electrodes before and after 100 cycles. (d) and (e) SEM images of the $\mathrm{rGO} / \mathrm{LaPO}_{4} / \mathrm{LVO}$ electrode before and after 100 cycles.

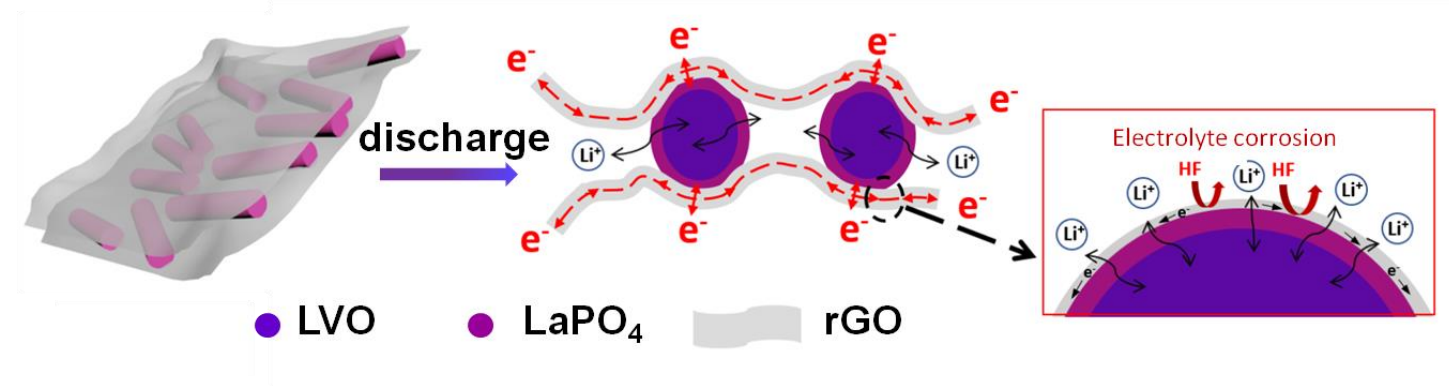

Figure 6 The interfacial schematic diagram of LVO electrode with $\mathrm{rGO}$ and $\mathrm{LaPO}_{4}$ layer, which provide effective electronic transport path and protect electrode surface from electrolyte corrosion. 
Table 1. EIS fitting data of $\mathrm{LVO}$ and $\mathrm{rGO} / \mathrm{LaPO}_{4} / \mathrm{LVO}$ after $1^{\text {st }}$ and $100^{\text {th }}$ cycles

\begin{tabular}{ccccc}
\hline \multirow{2}{*}{ Cycles } & $\mathrm{LVO}$ & $\mathrm{LVO}$ & $\mathrm{rGO} / \mathrm{LaPO}_{4} / \mathrm{LVO}$ & $\mathrm{rGO} / \mathrm{LaPO}_{4} / \mathrm{LVO}$ \\
& $R_{\text {sei }} / \Omega$ & $R_{\text {ct }} / \Omega$ & $R_{\text {sei }} / \Omega$ & $R_{\text {ct }} / \Omega$ \\
\hline \multirow{2}{*}{1 st } & 45.5 & 379.8 & 37.4 & 98.2 \\
100 th & 963.2 & 970.2 & 555.8 & 634.5 \\
\hline
\end{tabular}


Supplementary Materials for

\section{Boosting the rate and cycling performance of $\beta-\mathrm{Li}_{x} \mathrm{~V}_{2} \mathrm{O}_{5}$}

\section{nanorods for Li ion battery by electrode surface decoration}

Pan-Pan Wang ${ }^{\mathrm{a}, \mathrm{b}, \mathrm{c}}$, Yue Du ${ }^{\mathrm{a}, \mathrm{c}}$, Bao-You Zhang ${ }^{\mathrm{b}}$, Yan-Xin Yao ${ }^{\mathrm{b}}$, Yu-Chen Xiao ${ }^{\mathrm{b}}$, Li-Jie Ci ${ }^{\mathrm{a}}$,

Cheng-Yan Xua, ${ }^{\mathrm{ab}, \mathrm{c}, *}$, Liang Zhen ${ }^{\mathrm{a}, \mathrm{b}, \mathrm{c}, *}$

${ }^{a}$ School of Materials Science and Engineering, Harbin Institute of Technology (Shenzhen),

Shenzhen 518055, China

${ }^{b}$ School of Materials Science and Engineering, Harbin Institute of Technology, Harbin 150001, China

${ }^{c}$ MOE Key Laboratory of Micro-Systems and Micro-Structures Manufacturing, Harbin Institute of Technology, Harbin 150080, China

E-mail: lzhen@hit.edu.cn (L.Z.); cy_xu@hit.edu.cn (C.Y.X.)

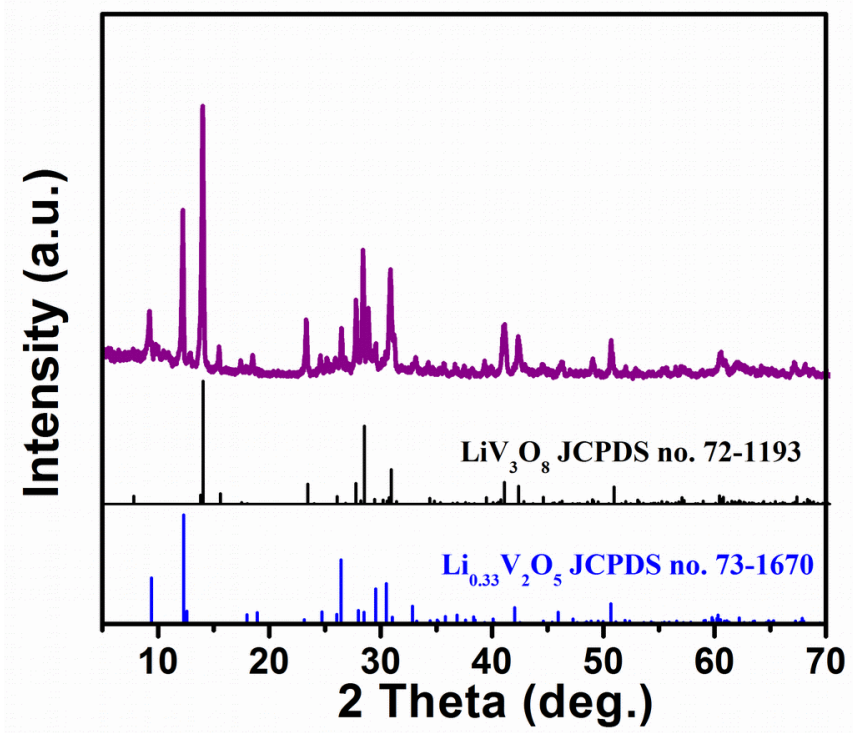

Figure S1 XRD pattern of rGO/LVO sample obtained by oven-drying. 


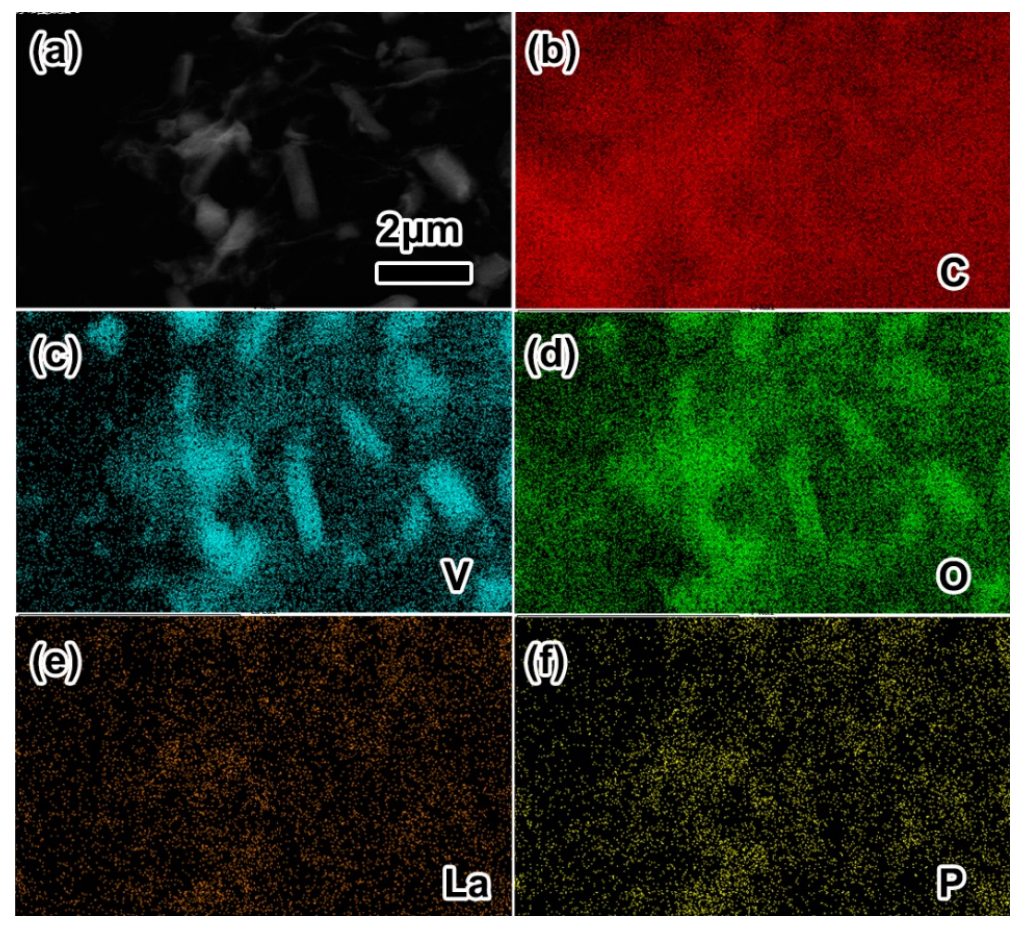

Figure S2 EDS mapping of $\mathrm{rGO} / \mathrm{LaPO}_{4} / \mathrm{LVO}$ sample.

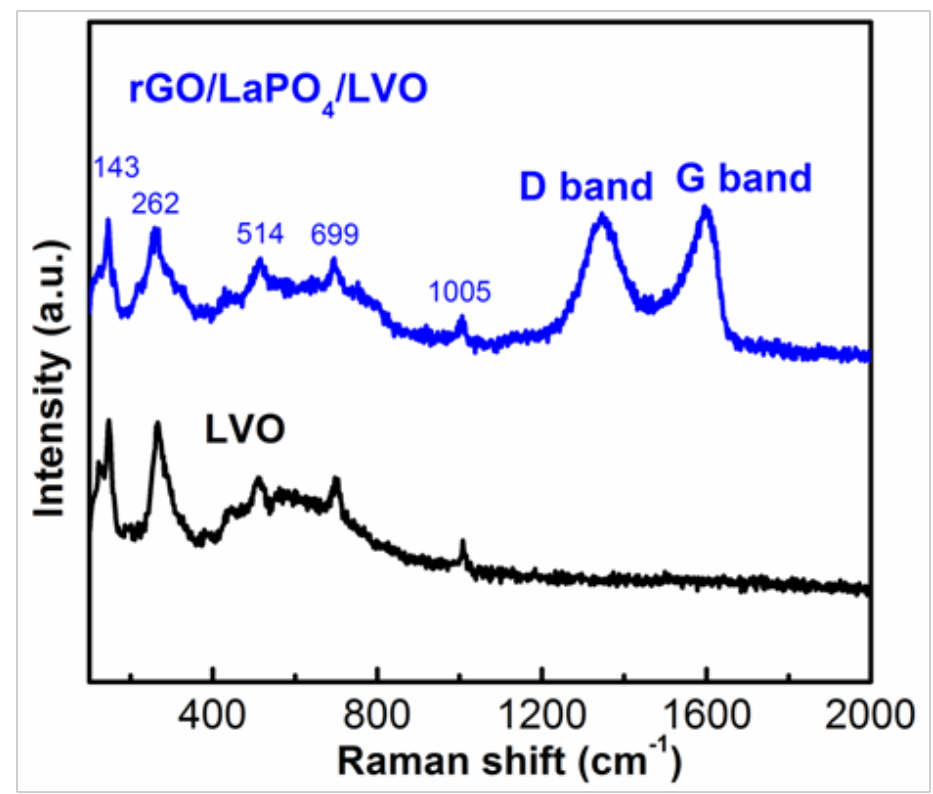

Figure S3 Raman patterns of the LVO and rGO-LaPO $/ / \mathrm{LVO}$ samples. The frequency mode at 143 , 262, 514, 699 and $1005 \mathrm{~cm}^{-1}$ are assigned to bond bending vibrations and the stretching vibrations of differing $\mathrm{V}-\mathrm{O}$ bonds in $\beta$-phase bronze $\mathrm{Li}_{x} \mathrm{~V}_{2} \mathrm{O}_{5}$ compounds. 

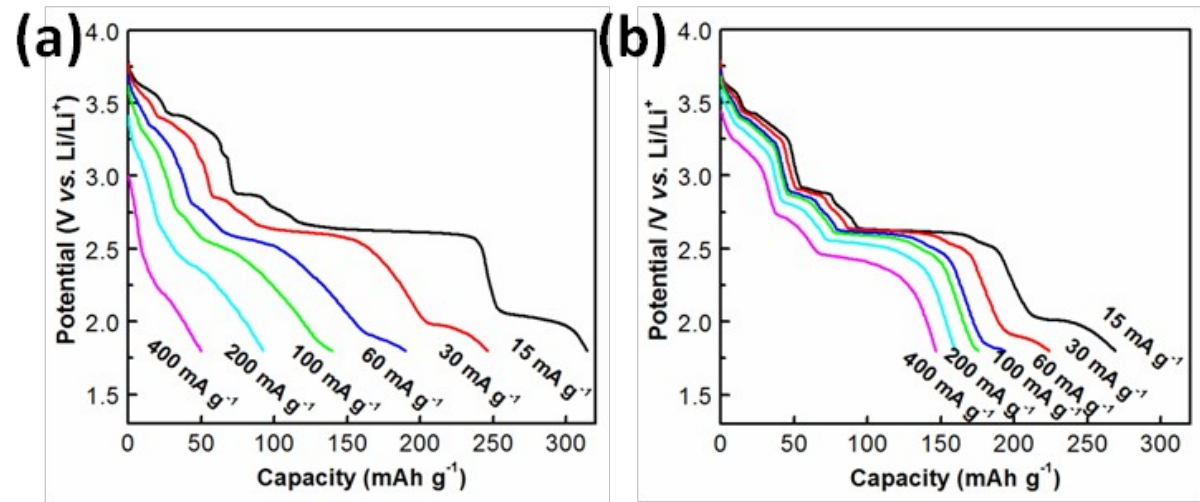

Figure S4 (a) Charge/discharge curves of the LVO and (b) rGO/LaPO $4 / \mathrm{LVO}$ electrodes at different current densities. 
